\title{
Semantic Web, Ubiquitous Computing, or Internet of Things? \\ A Macro-Analysis of Scholarly Publications
}

\begin{abstract}
Purpose - The aim is to investigate concepts that are used in depicting future visions of society, as afforded by technology, to (a) map the extent of their use, (b) examine the level of their dominance in different research areas and geographic boundaries, (c) identify potential overlaps, (d) analyse their longitudinal growth, and (e) examine whether any of the identified concepts has assumed an overarching position.

Design/methodology/approach - Fourteen concepts, each of which is used to depict visions of future information infrastructures, were identified. More than 20,000 scholarly documents related to eleven of these concepts (those with 20 or more documents) are analysed by various qualitative/quantitative methods.
\end{abstract}

Findings - The concepts most referred to are semantic web and ubiquitous computing (all years), and internet of things" (year 2013). Publications on some newer concepts (e.g. digital living, real world internet) are minimal. There are variations in the extent of use and preferred concepts based on geographic and disciplinary boundaries. The overlap in the use of these terms is minimal and none of these terms has assumed an overarching umbrella position.

Research limitations/implications - This study is limited to scholarly publications; it would be relevant to also study the pattern of usage in governmental communications and policy documents.

Social implications - By mapping multiplicity of concepts and the dispersion of discussions, we highlight the need for, and facilitate, a broader discussion of related social and societal implications.

Originality/value - This paper is the first to present a collective of these related concepts and map the pattern of their occurrence and growth.

Keywords - Internet, Information science, World Wide Web, Information society, Digital communications, Information strategy

\section{Introduction}

Certainly, the future is information technology rich, but how do we conceptualize our visions of tomorrow? In this paper, we identify a body of concepts that are commonly used in depicting visions of future information infrastructures and provide an overview of the scholarly publications that relate to these concepts. This can be seen as a support for social scientists engaging with such scenarios that are typically promoted by technologists, remote from social and societal reflections.

Internet-based technologies, digital media, and ubiquitous mobile access to these, have evolved rapidly over the recent years. Today, the number of Internet-based products, systems, services and objects has become too vast to count. In addition, complex connections and information sharing practices between these are becoming increasingly commonplace.

We have witnessed an explosion of Internet-based commerce (including mobile payments), navigation systems and location based services, RFID tags, sensors, intelligent home solutions, CCTVs, cookies, beacons, apps, and other tracking technologies. It is not difficult 
to get a sense of some of the technological possibilities that will become a reality in a near future. Flexible computer screens inbuilt in our clothing, run by alternative sources of energy, are not far off. In association with visions of future information infrastructures, various concepts have been coined and promoted and potential technological products and services are presented by different scholars and technologist. Rainie and Wellman, for example, offer the following description:

Ubiquitous computing, sometimes called "the internet of things" (or "everyware"), describes human-computer interaction that goes beyond personal computing to an environment of objects processing information and networking with each other and humans. Objects would share information: appliances, utility grids, clothing and jewelry, cars, books, household and workplace furnishings, as well as buildings and landscapes. They would learn additional information and preferred methods of use by gathering data about people who are in their environment. (Rainie \& Wellman, 2012: 279 - italics added)

However, the use of related concepts has not been coordinated and confluent; and as exemplified by the excerpt above, nor has there been clarity in definitions of, and differences between, various concepts. Are the concepts of ubiquitous computing, the internet of things, and everyware synonymous? If so, are there common forums in which they are discussed? If not synonymous, what are their differences?

These future visions involve concerns of much importance at a societal level and are in need of further investigation and critical reflection. For a pensive discussion of potential future paths, we need to be aware of the different concepts, and their specificity. Each frame of reference highlights some and blurs other aspects. As formulated by Athique "we should always remain attentive to the way in which the foundational terms of our analysis inevitably shape our view of the subject matter, as well as the conclusions we draw" (2013: 261). The term 'smart' as in smart phone or smart environment, for example, is often used to highlight positive aspects such as useful enablement, connectivity, and device interventions leading to human convenience. Other terms could have been used instead to draw attention to negative aspects such enabling mass surveillance, commodification of personal user information, or heightening asymmetrical power structures, and so on. The potential implications of the new technologies envisioned for the future are grave. It is imperative that the scholarly community, the politicians, general public and other stakeholders are engaged in dialogue and the shaping and reshaping of the outcomes. However the popping up of new concepts has not been accompanied with scholarly reflection and clarification of terms. Lakoff and Johnson (2003 [1980]) point out the importance of the concepts that we use, not only as a matter of intellect but also as having a central role in defining our everyday realities. They further state, "[a]ny adequate theory of the human conceptual system will have to give an account of how concepts are (1) grounded, (2) structured, (3) related to each other, and (4) defined" (Lakoff and Johnson, 2003 [1980]: 106).

It is beyond the scope of this paper to attend to these four tasks. What we instead propose to do here is to present an overview of the existing concepts to facilitate follow up attempts in bringing more clarity and rigor in definitions of these concepts. We hope that a clearer view of the landscape, in which these concepts are interacted with, would allow the extension of critical discussions on social issues related to these technological developments. A fragmented discussion has already started on different issues and in relation to different concepts. To help assemble related discussions we need to identify which are the concepts 
and where are the discussions taking place. As a first step, a clearer overview is needed. That is what we aim to provide in this paper. In other words, the overall purpose is to gain a better understanding of the terms that are being used in depiction of visions of a technology rich future. We do this through a macro-analysis of related scholarly publications. The questions addressed are:

- What concepts are used in depicting future visions of society, as afforded by technology?

- What are the central ideas within these visions and do they relate to one another?

- To what extent are these concepts used?

- Is there a significant overlap in the use of these terms?

- What are the levels of presence of these terms in different research areas?

- Is the adoption of these terms equally spread over disciplinary and geographical boundaries?

- How are the patterns of longitudinal growth for each of these concepts?

- Has any concept assumed an overarching, umbrella position?

In the following we will account for methodological aspects of this study and then address the first two of these questions by presenting a flora of different concepts. Thereafter we present some results, focusing on the character, diversity, dispersion, and growth of the concepts as visible in Web of Science data. The paper concludes with a short discussion.

\section{Study approach}

This study is informed by the established traditions of bibliometrics within the field of library and information science. We intend to bring clarity to, and gain a better understanding of, a suit of different concepts that address seemingly related concerns. We propose to achieve this by studying the scholarly publications within which these concepts are discussed. A central assumption within bibliometrics is that citations in scholarly publications can shed light on the process of scientific development and structure of science (Garfield, 1979). Accordingly, aggregated citation data at document level is typically used in bibliographic coupling and cocitation analysis (Kessler, 1963; Small, 1973) in order to identify research fronts (Small and Griffith, 1974). Co-citation at author level has been used in mapping of intellectual structures (McCain, 1986; White and Griffith, 1981). The intellectual structure could also be analysed at higher levels of aggregation such as journal and other sources for the publications (McCain, 1991a, 1991b). Even higher levels of aggregation such as organization or country of affiliation could be used.

Following these thoughts, we apply some established bibliometric methods coupled with a qualitative analysis of bibliographic data, in order to map the landscape of terms associated with visions of an information technology rich future. As Boyack (2004) notes, most mapping applications are directed toward dynamics of disciplines, focusing on the analytical units of authors, documents, journals, words and indicators. Although all of these are targeted in the current study, the aim is not to describe disciplines. The idea is rather to discuss spatialtemporal relationships between uses of a multitude of seemingly similar concepts. As such, our work connects to three of the nine applications of bibliographic research suggested by Connaway and Powell (2010, 82): improving the bibliographic control of a literature, identifying a core literature and tracing the spread of ideas/growth of a literature. Our perspective is also inspired by the challenge posed by Van Raan (2005) in going beyond descriptions of disciplines by identifying specific patterns at a meta-level. This is done by 
reviewing the clustering of information carriers (publications) together with the information elements (concepts). The clustering of information elements can be pursued through coconcept analysis and conclusions to be drawn regarding intellectual affinity. This is something that we attempt in this study. We place the focus of this paper on presenting some of the trends in the use of concepts within disciplinary and geographical boundaries and over time.

This study is an application of bibliometrics for the purpose of mapping an area of study rather than an engagement in a methodological discussion of bibliometrics. Even so, we are well aware of the limitations of bibliometric methods, such as indexed journal articles not being the only carriers of knowledge, or that there are differences in publication behaviours in different fields, and the many technical challenges associated with non-normalized data, name ambiguity, presence of duplicates, and so on. More importantly, we are aware that with the use of such methods we can only represent a limited view of a complex reality. Even so, accumulated experience has shown that the application of citation analysis can be a viable indicator of scientific performance (Van Raan, 2005: 26). Therefore, even considering the limitations of method, we believe, that our mapping could provide insights about the landscape within which these concepts have come about and the relevance of all these concepts for one another and the discussions of future information infrastructures.

\section{Flora of related terms}

By an extensive review of the literature and snowballing technique, we have identified 14 different terms used in depictions of technology rich future visions. However, as the numbers of scholarly publications on three of these terms were too small we place the focus of the presentation on the remaining eleven terms.

1. Ubiquitous computing (Ubicomp) - The idea of Ubicomp was born in the late 1980s based on a number of technological proposals at the Xerox Palo Alto Research Center (including large flat-panel screens that would be both computer displays and input devices) and ideas arising from anthropological studies of work practices (Weiser, 1991, 1993a, 1993b, 1995; Weiser et al., 1999). Ubicomp refers to a society in which human computer interaction is seamlessly and unnoticeably integrated into everyday life. It is suggested that workspaces can contain numerous computers that help people improve their performance. While earlier, humans would go to the computers and adapt social action to the technology, Ubicomp reverses the situation. It is the machines that adapt to the environment of humans (York \& Pendharkar, 2004). At the core of Ubicomp, lies an ideology in which computer technology is envisioned to be unobtrusively serving humans in the background not as personal assistants, but rather as an extension of one's capabilities (e.g. Weiser, 1993a: 76).

2. Pervasive computing - As the technological developments have advanced (especially concerning the mobile revolution), the vision of Ubicomp has been reiterated in terms of a somewhat synonymous concept, namely pervasive computing. This term seems to have its origin within industry (e.g. IBM Research, n.d.). In relation to this term, the focus is not so much on the vision as it is on technological issues. Based on a literature review Orwat et al. (2008) find pervasive computing to be "loosely associated with the further spreading of miniaturized mobile or embedded information and communication technologies (ICT) with some degree of 'intelligence', network connectivity and advanced user interface" (ibid: 2). Pervasive computing could be seen as a continuation of Ubicomp as many of the publications that discuss or try to define pervasive computing refer back to Weiser and his 
vision of the future (e.g. Saha \& Mukherjee, 2003; Satyanarayanan, 2001; Yachir et al., 2012). Regardless of this close connection, both terms are widely used and there are formal conferences, communities, and journals attached to each of these terms.

3. Ambient Intelligence (AmI) - The concept of Ambient Intelligence was invented by a team at Palo Alto Ventures comprising of Eli Zelkha, Brian Epstein, Simon Birrell, and Clark Dodsworth and first presented by their colleague Roel Pieper (see Zelkha \& Epstein, 1998) at the Digital Living Room Conference organized by Philips Research. AmI describes a world in which technology will be implicit and anticipatory. Rather than issuing instructions to technology, in order for it to do something that we wish, the technology is to know what we need and to do it without the need for instructions. In AmI, according to Augusto and Aghajan (2009: 1), the idea is that "by enriching an environment with technology (sensors, processors, actuators, information terminals, and other devices interconnected through a network), a system can be built such that based on the real-time information gathered and the historical data accumulated, decisions can be taken to benefit the users of that environment". This concept was later used by the Information Society Technologies Advisory Group (ISTAG), a group that provides independent advice to the European Commission, in their discussions of visions for the future (e.g. Ducatel et al., 2001). AmI is differentiated from Ubicomp in not just being about computing; rather it involves other technologies such as smart materials and other innovations that "truly integrate with life, in which our environments become wiser, more comfortable, and more compelling" (Zelkha \& Epstein, 1998). At the core of this vision is the idea of a "life-enhancing" environment that anticipates and fulfils "our" needs, without mediation, in order to make us more comfortable. This vision extends the range of technologies that are considered to go beyond computing.

4. Smart Environment(s) (SmE) - A closely related term is that of Smart Environment(s) (SmE) which according to Augusto, and Aghajan (2009: 1) "refers to environments that sense, perceive, interpret, project, react to, and anticipate the events of interest and offer services to users accordingly". Augusto, Nakashima and Aghajan use the term "to emphasize the physical infrastructure (sensors, actuators and networks) that supports the system" (Augusto et al., 2009: 2), where "user-centric data extraction and decision making” (Augusto et al., 2009: 11) is a premise. For Cook and Das (2005: 3) SmE "is able to acquire and apply knowledge about an environment and also to adapt to its inhabitants in order to improve their experience in that environment". Again, the user, and enhancement of user experiences are said to be central. As compared with other concepts, it is stated that while AmI "is more concerned with the specific techniques to make an environment behave intelligently, SmE is more related to the intelligent interconnection of resources and their collective behavior" (Augusto \& Aghajan, 2009: 1). There are also a number of other terms, such as Intelligent Environments or Responsive Environments, which are often used synonymously.

5. Ubiquitous Web - This concept first appears in scholarly literature from the late 1990s (e.g. Liu et al., 1998; Logenthiran et al., 1998) often to point to spreading use and ubiquitous access to the Web. In subsequent publications, this concept has come to refer to an integration of telephone and Web-based services (e.g. Huang et al., 2000) as well as context aware computing and personalization (e.g. Finkelstein et al., 2002). It is concerned with mobility and constant access to information: "any information at any time from any location" (Billsus et al., 2002: 34). A core idea is that available information is too plentiful and mobile device interfaces are restricted in size. If the full range of 
information were to be presented on mobile devices, it would burden the user rather than facilitate information access. Here, adaptive interfaces (that would learn from users' past behaviour and interests) and personalization are presented as solutions for mobile access to Web-based information (Billsus, et al., 2002). That is, only the most relevant information (based on user's previous interests) is to be presented on the limited space available on mobile interfaces. Ubiquitous Web is somewhat narrower than the concept of ubiquitous computing in that it places focus mainly on mobile, Web-based information use, rather than a wider range of technologies. However, a more important difference is the introduction of directed advertising and commercialisation of the Web-based information by presenting that direct advertising 'benefits considerably' from personalization (e.g. Billsus, et al., 2002: 37). Here, a different sense of user emerges, where the technology could benefit commercial corporations as the user, rather than the individuals who seek and use Web-based information.

6. Semantic Web - With start in early 90s, Semantic Web builds on the idea of World Wide Web (W3) created by Tim Berners-Lee (later described in e.g. Berners-Lee et al., 2001) and is essentially an extension of the idea of the Web. Whereas previously content was designed to be read by humans, Semantic Web builds on the idea of designing contents for access and meaningful manipulations by computer programs. Semantics would be encoded into Web pages enabling Semantic Web agents to survey the Internet and assist humans with information access and carrying out various tasks. Personal semantic agents would fluently serve as our mediator with technology for improved coordination and a wider range of services. The idea of semantic agents suggest a type of 'personal assistant', which was argued by Weiser (1993a: 76) not to be the vision of Ubicomp. Regardless, the focus in Semantic Web is placed on Web-based information, information access, knowledge representation, and semantic codes appropriate for technology intervention. These differentiate the visions of Semantic Web and that of Ubicomp both in area of focus, and extent of innovations and issues included in the vision.

7. Internet of Things (IoT) - The Internet of Things, most likely coined in 1999 (see Ashton, 2009) [1], was initially little more than an adoption of Ubicomp to the technology of the Internet. With time, this notion has been considerably broadened. In the simplest terms, IoT seems to envisage a society where all members have access to a full-fledged Internet environment populated by self-managing, smart technology anytime and anywhere. As defined by Sundmaeker et al. (2010:41) "Internet of things (IoT) is a dynamic global network infrastructure with self-configuring capabilities based on standard and interoperable communication protocols where physical and virtual 'things' have identities, physical attributes, and virtual personalities and use intelligent interfaces, and are seamlessly integrated into the information network." More recently and within the context of EU, various related issues are frequently brought together with these denotations by policymakers (For instance in the European framework program on the "Future Internet"), giving this concept dominance in policy discussions and technological agendas in European Union (e.g. Commission of the European Communities, 2008, 2009; The Council of Europe, 2009). In IoT, "smart things/objects" are expected to become active participants in business, information and social processes. They are enabled to interact and communicate among themselves and with the environment by exchanging data and information "sensed" about the environment. They are to react autonomously to the "real/physical world" events and to influence it by running processes that trigger actions and create services with or without direct human intervention. 
One technological development with obvious implications for IoT is the updating of the Internet protocol (from IPv4 to IPv6 increasing the IP address size from 32 bits to 128 bits). This transformation would allow each individual on earth to have $3.4 \times 10^{38} \mathrm{IP}$ addresses (e.g. Chen et al., 2006) at his or her disposal; all one's "things" can have individual Internet access. This would enable everyday objects to, not only, be identified in Internet catalogues, but they would also have their own IP addresses. This constitutes a dramatic expansion of the idea of IoT.

8. Real world Internet (RWI) - In association with IoT and various projects financed under European Framework Programme 7, another closely related term is Real world Internet. Here the focus is placed on the integration of "real world" into the Internet where wireless sensor technologies and networked embedded devices extend interaction between physical and virtual worlds, enabling event-based environmental intelligence. What is highlighted is a shift from human centric information exchange to service-provisions where users are machines. In this vision, the concept of identity is extended to objects, where ubiquity of object discovery and other services are supported by information exchange and collaboration between artefacts. In this vision, devices are seen as both "consumers and producers of content” (Position Paper: Real World Internet, 2009).

Generally, the main difference between the notions of RWI and IoT is in the bounds of their focus. RWI provides the vision for physical-virtual interconnection. A number of other concerns are similarly addressed under related but separate terms such as Internet of Services (IoS - investigating wide and easy access to IT based services) and Internet of Energy (IoE - investigating E-energy models for future). Each of these concepts places the focus on a specific area, but they can each be considered as a sub-area of IoT. In all of these visions, Internet forms the core technology.

9. Web of Things - This concept follows the idea of IoT, and builds on the success of Web 2.0 mashup applications to suggest a similar approach for integration of devices to connect the Web allowing both physical and Web-based things to be connected to virtual resources (Guinard \& Trifa, 2009). The focus here is on a Web-based environment and hence the area of attention of this concept is not as broad as what is envisaged by IoT.

10. Digital Living - Not yet widely used, the notion of Digital Living, is a reminder of the ideas presented in the talks and workshops on digital living room initiated by Philips Research, and the idea of digital living without the bounds of place and time as presented by Negroponte in his book being digital (Negroponte, 1995).

11. System of systems (SoS) - This term appears in our dataset as far back as early 1970s, although the use of this term in those early publications is not in the sense that is the core of this paper (e.g. Ackoff, 1971- is concerned with a system of organizing those terms and concepts that in turn talk about systems). With the improvements in digital communications and the growth of local and wide area network techniques, SoS has evolved to relate increasingly to linked systems and connected devices. Judging by our dataset, SoS is repeatedly used in connection to military-related technologies and the US army's concept of Army After Next (AAN) (e.g. Badger et al., 2012; Kelley and Pei, 1999; Knichel, 2010). The following excerpt from the abstract of a paper by Marquet and Ratches (1998: 20) exemplifies this: 
The role of systems in the AAN that will gather information, process, store, fuse, and disseminate information and conduct information warfare will be emphasized and developed. New concepts for sensors and information system are described as well as their relationship to a system-of-systems for information dominance on the battlefield.

Accordingly, in our data we find a dominance of use of this term in the USA.

In addition to the above terms, a few others are of relevance, but which are excluded from presentation in the upcoming sections due to the very small number of publications on them.

One such term (with 11 documents in WoS) is Everyware, which has been discussed at some length in a book by Greenfield who describes it in terms of "information processing embedded in the object and surfaces of everyday life” (Greenfield, 2006: 1). As such processing powers of multiple everyday devices such as the coffee pot, the garment, etc, come together invisibly, rendering our homes, workplaces or the street to become "sites of processing and mediation". All the information one may need will be available anywhere at any time appropriate to the location and context. This situation is well in line with scenarios described by other terms presented above. It is of interest that similar to what we propose, Greenfield argues that there is an acute need "for a more sensitive description of the terrain" (ibid: 3). The present paper is a positive step towards an overview mapping of the terrain.

Another related term (with 5 documents in WoS) is that of Internet of people (Harbor Research, 2010), which similarly entails intelligent devices collaborating with each other as well as with people. A further concept (with only 1 document in WoS) has been suggested by the UK Future Internet Strategy Group: the Internet of People and Things (Townsend, 2011). The emphasis is on allowing a steady stream of personal data from each individual and his/her interaction with various devices in everyday life in order to customize services according to individual needs. Central to this vision is also development of cloud computing as service, platform and infrastructure. It is suggested that this ensures interoperability, fluid collaboration, flexibility, mobility and access to huge computer power.

These are the terms that we have identified as those more commonly used. The presence of so many well-established similar concepts is an interesting phenomenon that seems to be an indicator of numerous research traditions unconnected with each other. This is particularly quaint as most of the concepts seem to (as we shall see) grow out of discussions within computer science.

In theorising intellectual organization of sciences, Whitley (2000) presents the concept of low mutual dependence, which refers to research fields/discussions that lack a common set of instruments for measuring in developing theory. Although the documents related to each of the above-mentioned concepts do not represent established scientific fields, still, inspired by Whitley's idea, we investigate the extent and overlap of use of these concepts in scholarly publications. We also examine the relationships between the related scholarly articles and associated disciplinary, institutional and geographic affiliations as well as the longitudinal growth of each of the terms.

\section{A macro-analysis of scholarly publications}


The study started with reviews of a large body of documents comprising of scholarly publications, professional journals, blogs, news articles, official reports, and more. Based on these and in discussions with colleagues a snowballing process was initiated and 14 relevant concepts were identified.

To gather the empirical basis for the study, individual searches were done for each of the 14 concepts. As the numbers of publications on 3 of the terms were very small, those were excluded from the analyses below. The source used was Web of Science (WoS) and included the following databases: SCI-EXPANDED, SSCI, A\&HCI, CPCI-S, CPCI-SSH. The time span for all the searches was set to 1900 - 2013 [2].

Based on this material, we have conducted a macro-analysis consisting of various bibliometric analyses in conjunction what could be called a qualitative analysis of quantitative descriptive bibliographic data, as presented below.

\section{Extent of use of different terms}

To get a sense of the extent of use of the different terms, Table 1 represents the search strings and the number of retrieved items related to each of the terms.

Table 1

Search strings and number of retrieved items

\begin{tabular}{llr}
\hline No. & Search string & Items \\
\hline \# 01 & TS=“ambient intelligence” & 1,360 \\
\# 02 & TS=“digital living” & 38 \\
\# 03 & TS=“"internet of things” & 1,624 \\
\# 04 & TS=“"pervasive computing” & 2,972 \\
\# 05 & TS=“"real world internet” & 42 \\
\# 06 & TS=“semantic web” & 9,497 \\
\# 07 & TS=“"smart environment*” & 716 \\
\# 08 & TS="system* of system*" & 1,255 \\
\# 09 & TS=“ubiq* computing” & 4,332 \\
\# 10 & TS=“"ubiquitous web” & 87 \\
\# 11 & TS=“web of things” & 74
\end{tabular}

As presented, the number of documents on each term spans from 38 items on "digital living" at the low end, to 9497 items on "semantic web" at the high end.

The total number of retrieved items, when searches were done on each search terms separately, was 21,997. However, when a combined search was conducted for theses 11 search terms in one go, the retrieved items came up to 20,942, which indicated an overlap between the occurrences of different terms within 1,055 documents.

It should be noted that in the presentations that follow, multiple authors, document types, institutional affiliations, countries, subject and research areas, etc. have been involved. This means that the sums of individual parts (e.g. sums of all documents listed under each document type) exceeds the number of items in our dataset (Web of Science, 2007). Potential summation discrepancies are due to this rather than error in our presentations.

To examine, the closeness of use, and whether some of the terms presented above may be used interchangeably, we then studied the level of overlaps in occurrence of the terms. For 
this, we used the facilities offered within WoS to identify those articles that refer to more than one of these concepts. Table 2 represents the extent of pairwise overlap in concept-use [3].

Table 2

Concept use overlap

\begin{tabular}{|c|c|c|c|c|c|c|c|c|c|c|c|}
\hline \multirow[b]{2}{*}{$\begin{array}{l}\text { ambient } \\
\text { intelligence }\end{array}$} & & & & & & & & & & & \\
\hline & 1369 & 0 & 11 & 74 & 0 & 21 & 83 & 0 & 181 & 0 & 2 \\
\hline \multirow{4}{*}{$\begin{array}{l}\text { digital living } \\
\text { internet of } \\
\text { things } \\
\text { pervasive } \\
\text { computing } \\
\text { real world } \\
\text { internet }\end{array}$} & 0 & 39 & 0 & 0 & 0 & 2 & 0 & 0 & 0 & 0 & 0 \\
\hline & 11 & 0 & 1708 & 23 & 1 & 24 & 30 & 2 & 49 & 1 & 28 \\
\hline & 74 & 0 & 23 & 2979 & 0 & 59 & 56 & 1 & 287 & 5 & 6 \\
\hline & 0 & 0 & 1 & 0 & 42 & 0 & 0 & 0 & 0 & 0 & 0 \\
\hline \multirow{3}{*}{$\begin{array}{l}\text { semantic web } \\
\text { smart } \\
\text { environment* } \\
\text { system* of } \\
\text { system* }\end{array}$} & 21 & 2 & 24 & 59 & 0 & 9549 & 10 & 7 & 86 & 8 & 8 \\
\hline & 83 & 0 & 30 & 56 & 0 & 10 & 726 & 1 & 69 & 0 & 2 \\
\hline & 0 & 0 & 2 & 1 & 0 & 7 & 1 & 1266 & 1 & 0 & 0 \\
\hline ubiq* computing & 181 & 0 & 49 & 287 & 0 & 86 & 69 & 1 & 4343 & 9 & 5 \\
\hline \multirow{2}{*}{$\begin{array}{l}\text { ubiquitous web } \\
\text { web of things }\end{array}$} & 0 & 0 & 1 & 5 & 0 & 8 & 0 & 0 & 9 & 87 & 1 \\
\hline & 2 & 0 & 28 & 6 & 0 & 8 & 2 & 0 & 5 & 1 & 76 \\
\hline
\end{tabular}

As shown, although there is an overlap, considering the total number of retrieved documents, this overlap is relatively minimal (around $5 \%$ of the total). This indicates that although these terms typically describe similar phenomena, the related literatures are disjointedly dispersed over a large number of terms. This can be seen as an indicator of low mutual dependency (Whitley, 2000), i.e. that different traditions appear free to develop conceptual frames independently of other approaches investigating the same phenomena. The highest overlap was found in the use of the two terms of "ubiq* computing" and "pervasive computing". This could indicate a closer affinity between these terms as compared with others.

To examine this indication, an author co-citation analysis was conducted. From the 111,127 first-authors cited by the documents in our dataset, 2986 authors were cited 20 times or more. The co-citation map (Figure 1) graphs the authors that are most cited within our dataset, regardless of whether the cited documents are internal or external to our material. The larger the nodes, the more citations are received by the respective author's published items. The closeness of the nodes relates to how often pairs of authors are cited together.

Two names stand out: 'berners-lee t', and 'weiser m'. While they are each cited heavily, they are seldom cited together within this set. This is congruent with knowledge of each author's oeuvre as presented earlier, indicating a gulf between the publications on terms "semantic web" and "ubiquitous computing". This is in line with the findings presented earlier (Table 2) regarding little overlap in the use of those terms. 
In a close third position we find 'horrocks, i', whose work on OWL or Web Ontology Language is closely related to the Web and hence, the closeness in the placement of the Horrocks and Berner-Lee.

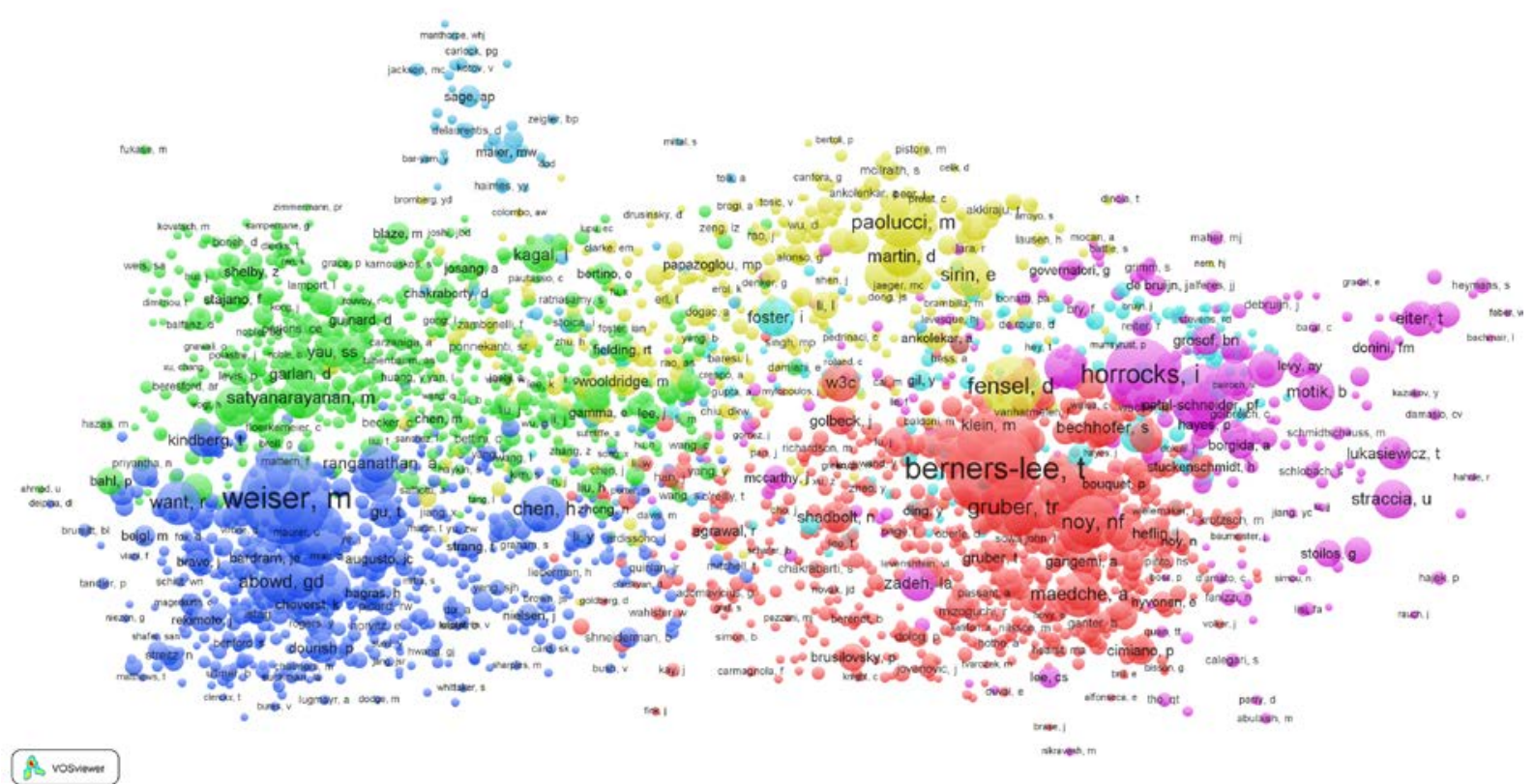

Figure 1. Author co-citation analysis.

\section{Co-concept analysis}

Following the indications of the previous section, we proceeded to further investigate potential separations between publications on different topics. One way of examining the topics discussed is to go by the keywords that authors ascribe to their work. In our data set, we identified 581 author-assigned keywords that each occurred more than 10 times. We conducted a co-occurrence analysis in $\mathrm{Sci}^{2} \mathrm{Tool}$ (Sci $\left.{ }^{2} \mathrm{Team}, 2009\right)$ and visualised the results in Gephi, using the Force Atlas algorithm (Bastian et al, 2009) based on these (Figure 2).

The results of this analysis support what was indicted in the previous section. Two separate areas are discerned. One group, which is more homogenous, includes terms such as 'Semantic Web', 'Ontology', 'Web Services' and so on. The other group includes several of the terms presented above such as 'Ubiquitous Computing', 'Internet of Things', 'Pervasive Computing', 'Ambient Intelligence'. It is of interest that there are a number of terms such as 'Rfid', 'Security', 'Privacy', 'Sensor' and so on that are intermingled within the second group, indicating their closeness with, and importance for, the mentioned terms. Yet, (as further highlighted in later sections) these terms exist in separation from one another. One further point to note is the distance between 'System of Systems' and the other terms highlighted in that figure. 


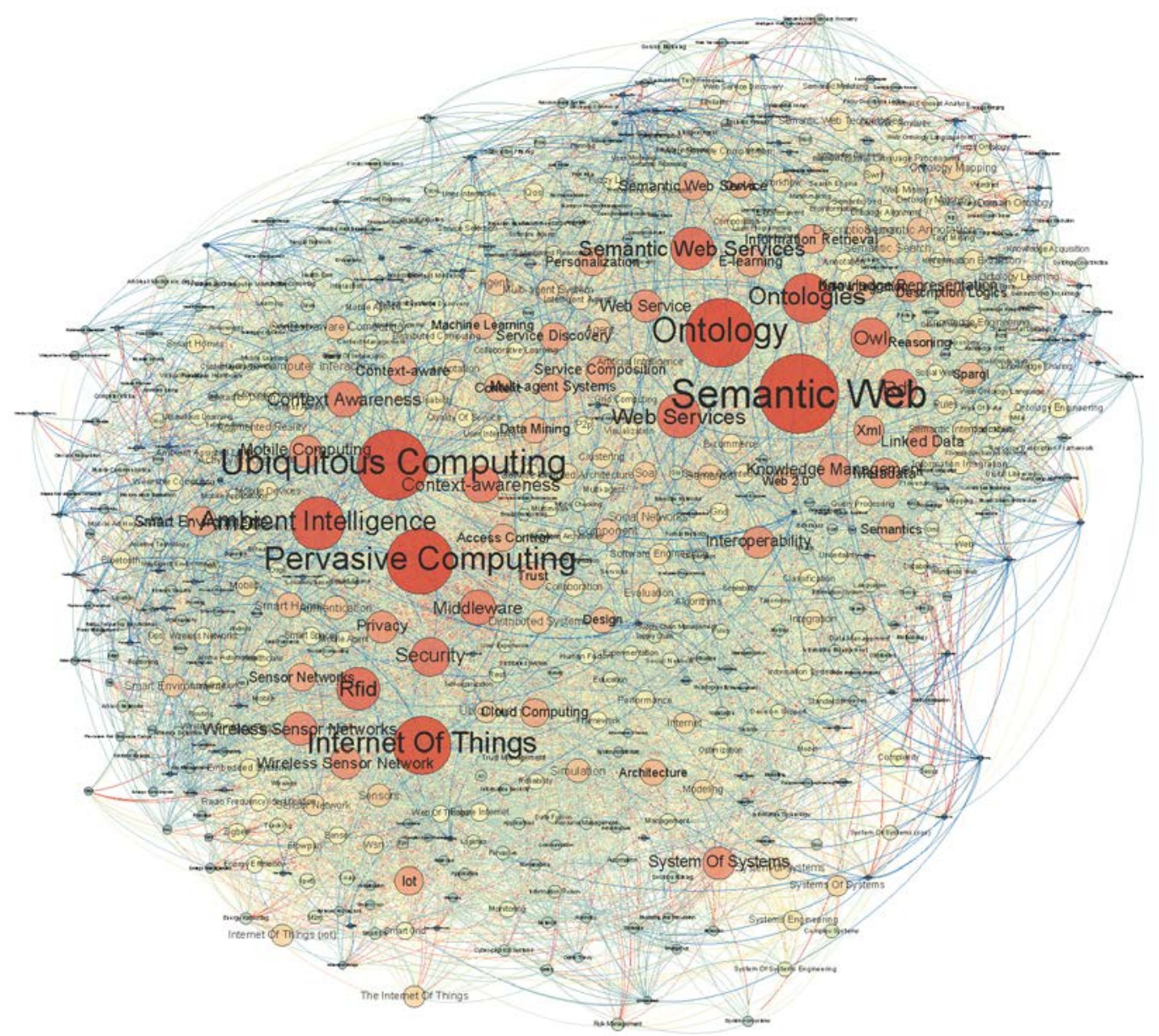

Figure 2. Co-word analysis of 581 author-ascribed keywords occurring more than 10 times in the set. The size of the nodes and the intensity in the colour are indicative of the extent of occurrences.

The above analysis is based on author-ascribed keywords; another way of examining the topics of discussion within the material is to analyse the actual words that appear in the documents. We conducted a co-word analysis of 204,256 noun phrases, occurring in titles and abstracts of the dataset, using VOSviewer (van Eck \& Waltman, 2011). After some data treatment [4], 1,254 terms were identified that occurred 50 or more times. Using the built-in relevance measure in VOSviewer (which omits terms frequently occurring in all documents, such as 'paper', 'study', 'result'), 752 terms were selected for the visualisation in Figure 3a. The more frequently each pair of phrases occur together, the closer they are plotted. Font size of the phrases relates to the number of times that each phrase occurs in the set.

In the heat map (Figure 3a), it is useful to adopt a geographic terminology to describe what is seen. Here we find two elevated areas in the "Pangea-shaped" landmass with a marked rift between them that corresponds to two main clusters in the figure. To the right, the elevated area relates to "semantic web", "ontology", “domain", and "knowledge" that very much correspond with the co-citation map of authors (Figure 1), where Berners-Lee and Horrocks were found as focal points. To the left a rather more heterogeneous area, centring on "environment", "device", and "sensor" is seen, as well as three of the specified search terms in our study. From the top there is "pervasive computing", "ubiquitous computing", and "internet of things". "Smart environment" is found slightly "north" of Internet of things, but due to the way the program omits overlapping terms, it is hidden below the more frequently occurring 'sensor'. Again, these findings correspond rather well with the co-cited author analysis that identified Weiser as an important node. In the lower part of Figure 3a, 'system of 
systems" is found in a less elevated area in the periphery of the map. Again this position indicates that the phrase is not as related to the discourse in the data set as some of the other terms.

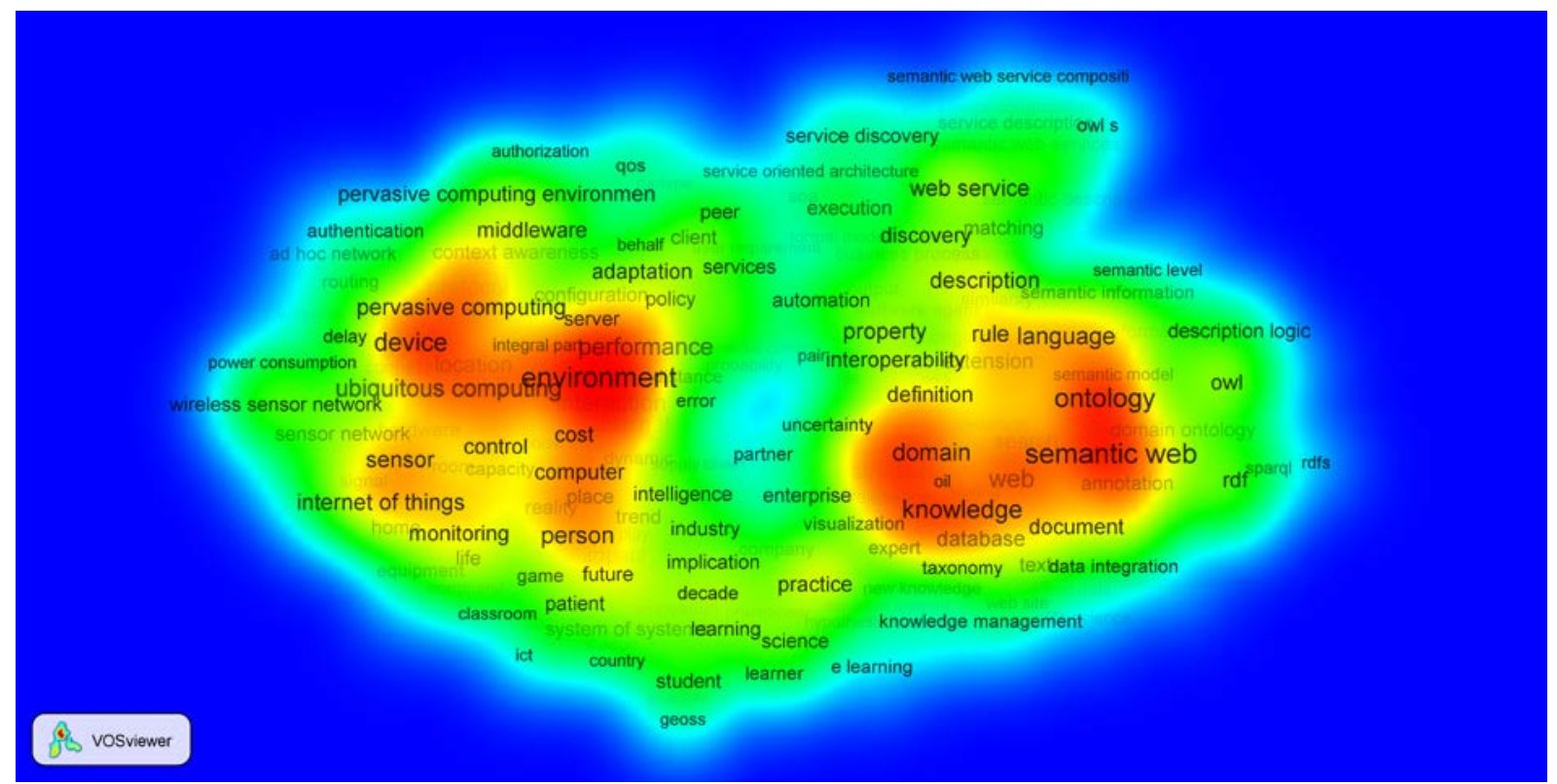

Figure 3a: Co-word mapping of 752 relevant terms in titles and abstracts: Heat map of areas.

Yet another way of visualising the same data is to identify clusters of phrases related to each other (Figure 3b); here, a precision of five clusters was chosen. Again the semantic web cluster in red is the most homogeneous, while the blue-green cluster, includes several different phrases from our search terms, and supports the interpretation that this is a heterogeneously complex cluster. The yellow cluster comprises of terms that relate to learning, science, knowledge, practice, but also industry, intelligence, and system of systems. The purple cluster on the top right hand comprises of terms relating to automation and service especially in connection with "semantic web" issues.

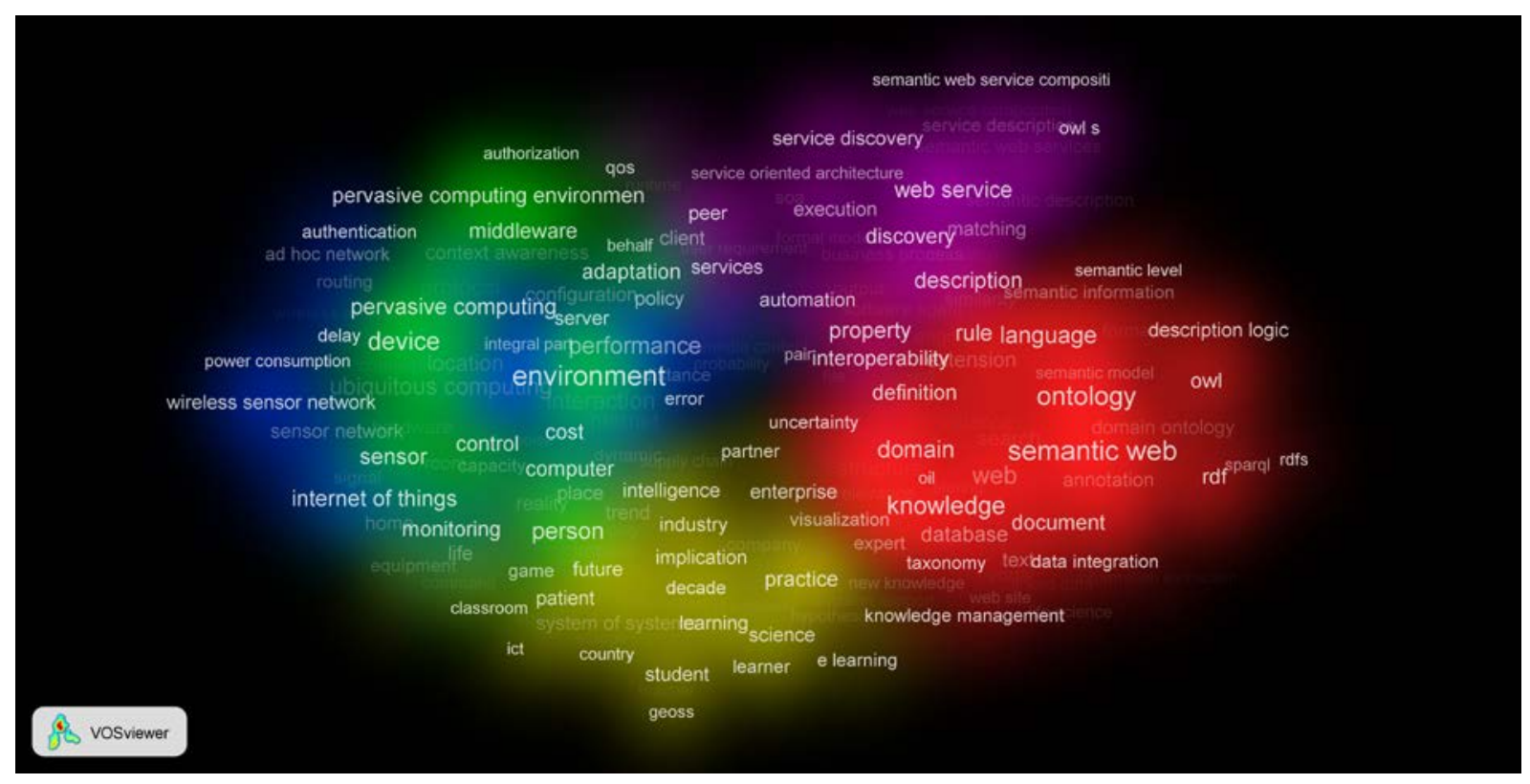


Figure $3 \boldsymbol{b}$ : Co-word mapping of 752 relevant terms in titles and abstracts: Cluster view of connected areas.

Both Figures 3a and 3b suggest a close-knit treatment of the term "semantic web" and related issues. The mix of several different terms bundled together in close proximity of each other on the left, indicate an affinity between those terms. The question arises as to whether there is a united community in which those terms are discussed. To gain some insight into this, we will examine the publication patterns in the following sections.

\section{Document types}

To learn more about publication trends, we examined the document types as indicated in WoS. We found proceedings papers to be dominant. This could relate to the speed of technological progress and that the time lapse involved in production of articles may be undesirable. As shown in Table 3, each of the document types from "Review" onwards stands for less than $1 \%$.

Table 3

Document type divisions

\begin{tabular}{rrr}
\hline Document Types & Records & \multicolumn{1}{c}{$\mathbf{\%}$} \\
\hline Proceedings paper & 15,242 & 72.88 \\
Article & 7,214 & 34.44 \\
Editorial material & 388 & 1.85 \\
Review & 169 & 0.81 \\
Book review & 58 & 0.28 \\
Meeting abstract & 40 & 0.19 \\
News item & 18 & 0.09 \\
Letter & 15 & 0.07 \\
Book chapter & 11 & 0.05 \\
Correction & 3 & 0.01 \\
Software review & 2 & 0.01 \\
\hline
\end{tabular}

At times, dominance of proceeding papers can be an indicator of high mutual dependence, where ideas are typically presented and discussed at shared international conferences. However, in relation to these concepts the conferences are diverse, as will be presented in the next section.

\section{Diversity in the choices of publications}

To get a better sense of the publications in which the discussions are taking place, document sources were examined. As shown in Table 4, the dominance of Lecture Notes in Computer Science (LNCS) is very marked as it totals in 3,542 documents. Together with the next two sources they collectively form about $22 \%$ of the total number of papers. While this is quite remarkable, it should be noted that each of these could be labelled meta-publications that primarily publish conference proceedings from a wide variety of different conferences. Accordingly, we found a wide dispersal in forums of discussions, as in total there were 6,111 different sources. Of those 6108 sources each host less than one per cent of the total publications. At the end of the list we find over 3,000 sources each hosting 0.005 per cent of the publications, hence forming a very long tail. 
Table 4

Document source title divisions ( $>100$ documents)

\begin{tabular}{lrr}
\hline Source & n & \% \\
\hline Lecture Notes in Computer Science & 3,542 & 16.9 \\
Lecture Notes in Artificial Intelligence & 682 & 3.3 \\
Communications in Computer and Information Science & 388 & 1.9 \\
Personal and Ubiquitous Computing & 184 & 0.9 \\
Journal of Web Semantics & 165 & 0.8 \\
Expert Systems with Applications & 149 & 0.7 \\
Advances in Intelligent and Soft Computing & 147 & 0.7 \\
International Federation for Information Processing & 137 & 0.7 \\
IEEE International Conference on Systems Man and Cybernetics Conference & 135 & 0.6 \\
Proceedings & 133 & 0.6 \\
Applied Mechanics and Materials & 132 & 0.6 \\
Semantic Web Research and Applications Proceedings & 126 & 0.6 \\
Advanced Materials Research & 115 & 0.5 \\
Frontiers in Artificial Intelligence and Applications & 110 & 0.5 \\
Journal of Universal Computer Science & 105 & 0.5 \\
Proceedings of The Society of Photo Optical Instrumentation Engineers SPIE & & \\
\hline
\end{tabular}

To further examine potential forums dispersion, we selected the top 50 sources (i.e. those hosting most number of documents) and determined the exact number of documents on each term, in each of these 50 sources. Additionally, we looked at the top 10 sources for each of the terms, and if these sources were not already included, we added them to the list. Again we identified the number of documents on each of the 11 terms in the newly added sources. By doing so, we ended up with a list of 70 sources that together accounted for 8,681 documents.

Of these 70 sources, 37 hosted documents related to 2 or more terms (Table 5), i.e. all the documents in the other 33 sources related to only one of the terms. The source "Lecture Notes in Computer Science" contained documents on all of the terms, although at varying degrees (from 1 document on "digital living" to 2,033 documents on "semantic web"). It is worth noting again that some of these meta-sources comprise papers presented at a wide variety of conferences. These results indicate a limitation of forums in which overarching cross-conceptual discussions take place.

Table 5

Sources with highest number of publications in which two or more of the terms have been discussed. 


\begin{tabular}{|c|c|c|c|c|c|c|c|c|c|c|c|}
\hline Source & $\sum_{0}^{\frac{0}{0}}$ & 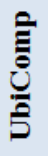 & $\Xi$ & 疍 & 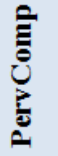 & 트 & $\underset{\tilde{S}}{\tilde{2}}$ & $\frac{\sqrt[E]{\theta}}{3}$ & $\frac{0}{0}$ & $\frac{3}{3}$ & $\sum_{\simeq}$ \\
\hline lecture notes in computer science & $\checkmark$ & $\checkmark$ & $\checkmark$ & $\checkmark$ & $\checkmark$ & $\checkmark$ & $\checkmark$ & $\checkmark$ & $\checkmark$ & $\checkmark$ & $\checkmark$ \\
\hline coms in computer \& info science & $\checkmark$ & $\checkmark$ & $\checkmark$ & $\checkmark$ & $\checkmark$ & $\checkmark$ & $\checkmark$ & $\checkmark$ & & & \\
\hline lecture notes in artificial intelligence & $\checkmark$ & $\checkmark$ & $\checkmark$ & $\checkmark$ & $\checkmark$ & & & & $\checkmark$ & & \\
\hline advances in intelligent \& soft computing & $\checkmark$ & $\checkmark$ & $\checkmark$ & $\checkmark$ & $\checkmark$ & $\checkmark$ & & & & & \\
\hline int federation for info processing & $\checkmark$ & $\checkmark$ & $\checkmark$ & & $\checkmark$ & & & & $\checkmark$ & & \\
\hline ieee int conf on systems man \& cybernetics conf proceed & $\checkmark$ & $\checkmark$ & $\checkmark$ & & $\checkmark$ & & $\checkmark$ & & & & \\
\hline journal of universal computer science & $\checkmark$ & $\checkmark$ & $\checkmark$ & $\checkmark$ & & $\checkmark$ & & & & & \\
\hline sensors & & $\checkmark$ & $\checkmark$ & $\checkmark$ & & $\checkmark$ & & $\checkmark$ & & & \\
\hline expert systems with applications & $\checkmark$ & $\checkmark$ & $\checkmark$ & & & & & & $\checkmark$ & & \\
\hline ieee intelligent systems & $\checkmark$ & & $\checkmark$ & $\checkmark$ & & & & $\checkmark$ & & & \\
\hline computer coms & & $\checkmark$ & & & $\checkmark$ & & & & $\checkmark$ & & $\checkmark$ \\
\hline computer & & $\checkmark$ & $\checkmark$ & $\checkmark$ & & & & & & $\checkmark$ & \\
\hline personal \& ubiquitous computing & & $\checkmark$ & $\checkmark$ & $\checkmark$ & & & & & & & \\
\hline applied mechanics \& materials & $\checkmark$ & & & & & $\checkmark$ & & & & $\checkmark$ & \\
\hline frontiers in artificial intelligence \& applications & $\checkmark$ & & $\checkmark$ & & & & & $\checkmark$ & & & \\
\hline journal of ambient intelligence \& smart environments & & $\checkmark$ & $\checkmark$ & $\checkmark$ & & & & & & & \\
\hline ieee pervasive computing & & $\checkmark$ & & $\checkmark$ & $\checkmark$ & & & & & & \\
\hline proceed of the society of photo optical instrumentation engin ... & & $\checkmark$ & & & & & $\checkmark$ & & $\checkmark$ & & \\
\hline ubiquitous intelligence \& computing proceed & & $\checkmark$ & & $\checkmark$ & $\checkmark$ & & & & & & \\
\hline proceed int computer software applications conf & $\checkmark$ & $\checkmark$ & & & $\checkmark$ & & & & & & \\
\hline proceed of spie & $\checkmark$ & & & & & $\checkmark$ & $\checkmark$ & & & & \\
\hline ieee internet computing & $\checkmark$ & & & & & $\checkmark$ & & & $\checkmark$ & & \\
\hline studies in computational intelligence & $\checkmark$ & $\checkmark$ & & & & & $\checkmark$ & & & & \\
\hline ambient intelligence proceed & & $\checkmark$ & $\checkmark$ & $\checkmark$ & & & & & & & \\
\hline int journal of ad hoc \& ubiquitous computing & & $\checkmark$ & & & $\checkmark$ & $\checkmark$ & & & & & \\
\hline assistive technology research series & & & $\checkmark$ & $\checkmark$ & $\checkmark$ & & & & & & \\
\hline 2012 ieee int conf on green computing \& coms conf on iot \& ... & & & & & & $\checkmark$ & & $\checkmark$ & $\checkmark$ & & \\
\hline ieee transactions on systems man \& cybernetics part a systems \& & & & $\checkmark$ & $\checkmark$ & & & $\checkmark$ & & & & \\
\hline $20083 \mathrm{rd}$ int conf on pervasive computing \& applications v1\&2 & & & & & $\checkmark$ & & & & & $\checkmark$ & \\
\hline pervasive \& mobile computing & & & & $\checkmark$ & $\checkmark$ & & & & & & \\
\hline studies in health technology \& informatics & $\checkmark$ & $\checkmark$ & & & & & & & & & \\
\hline ifip advances in info \& communication technology & $\checkmark$ & & & & & $\checkmark$ & & & & & \\
\hline ambient intelligence & & & $\checkmark$ & $\checkmark$ & & & & & & & \\
\hline multimedia tools \& applications & $\checkmark$ & $\checkmark$ & & & & & & & & & \\
\hline procedia computer science & & & & $\checkmark$ & & & $\checkmark$ & & & & \\
\hline info sciences & & $\checkmark$ & $\checkmark$ & & & & & & & & \\
\hline 2013 ieee 27 th int conf on advanced info networking \& & & & & & & $\checkmark$ & & $\checkmark$ & & & \\
\hline
\end{tabular}

\section{Dispersion of concept use in different research areas}

The research areas associated with the documents in our dataset were examined and a total of 120 different research areas were identified (noting that 44 items did not include data related to this). Of these, 105 research areas were each associated with less than $1 \%$ of the publications. Table 6 lists those research areas that were associated with 100 or more documents.

Table 6

An overview of research areas ( $>100$ documents)

\begin{tabular}{lrr}
\hline Research Areas & Documents & $\mathbf{\%}$ \\
\hline Computer Science & 16,857 & 80 \\
Engineering & 6,196 & 30 \\
Telecommunications & 3,913 & 19 \\
Automation Control Systems & 777 & 4 \\
Operations Research Management Science & 598 & 3 \\
Information Science Library Science & 555 & 3 \\
Business Economics & 488 & 2
\end{tabular}




\begin{tabular}{lrr} 
Education Educational Research & 413 & 2 \\
Imaging Science Photographic Technology & 341 & 1 \\
Medical Informatics & 296 & 1 \\
Mathematics & 287 & 1 \\
Robotics & 266 & 1 \\
Remote Sensing & 250 & 1 \\
Instruments Instrumentation & 241 & 1 \\
Mathematical Computational Biology & 240 & 1 \\
Materials Science & 209 & 1 \\
Health Care Sciences Services & 178 & 1 \\
Science Technology Other Topics & 175 & 1 \\
Chemistry & 160 & 1 \\
Biochemistry Molecular Biology & 156 & 1 \\
Optics & 142 & 1 \\
Physics & 136 & 1 \\
Environmental Sciences Ecology & 130 & 1 \\
Social Issues & 104 & 0.5 \\
\hline
\end{tabular}

A majority of the documents are situated within Computer Science, Engineering, and Telecommunications. Notably Information Science Library Science holds the sixth position in the list of research areas. Among the top 20 areas, one can find a number of articles classed as Business Economics, Education Educational Research, Medical Informatics, and Health Care Sciences Services. The technological dominance is overwhelming, while relatively few articles (at position 24 on the list), are attributed to Social Issues.

We further investigated the spread of each term over different research areas as well as the terms most used within each research area. Figures $4 \mathrm{a}$ and $4 \mathrm{~b}$ show the results for the top 10 research areas with most publications.

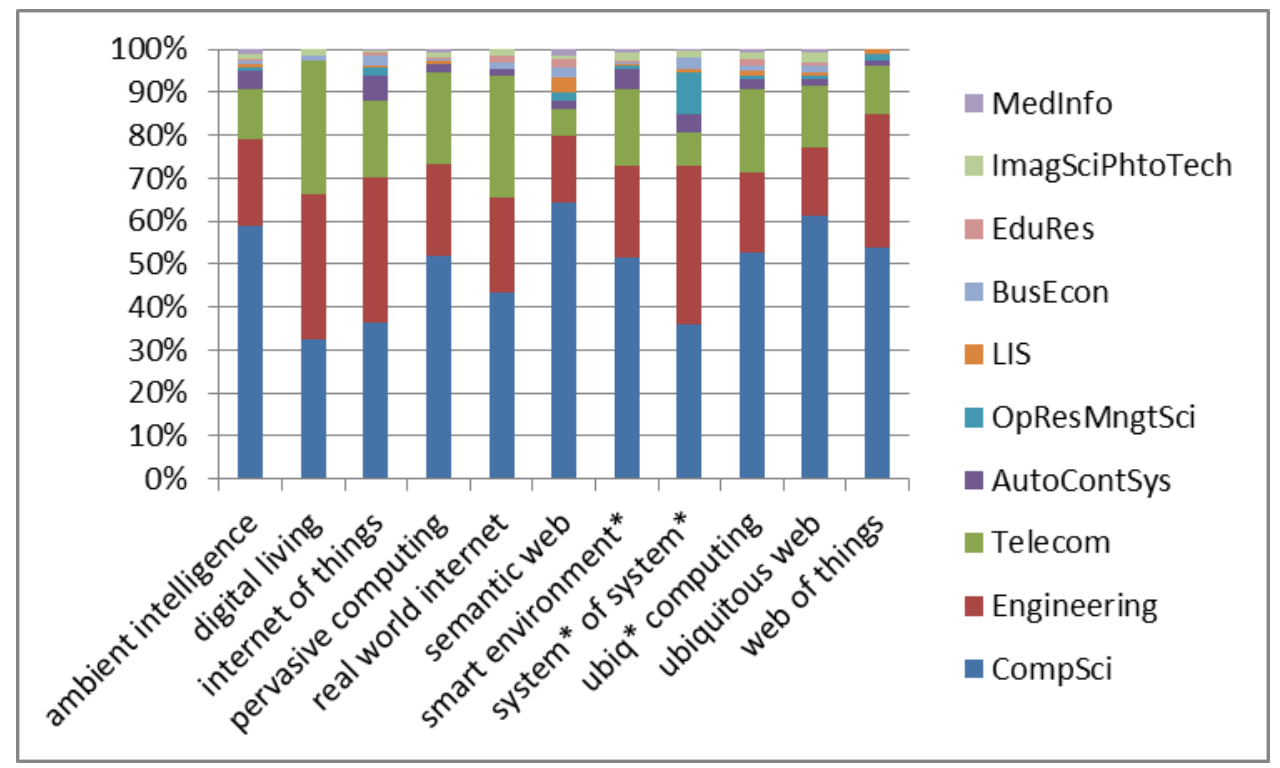

Figure 4a. Ratio of the top 10 research areas in association with each of the terms.

These figures show that computer science is a dominant research area for most of the terms but not for "digital living" and "system* of system*”. On the other hand, within almost all of 
the top 10 research areas, the term most referred to is semantic web but not in telecom where the terms "pervasive computing” and "ubiq* computing” are more dominant.

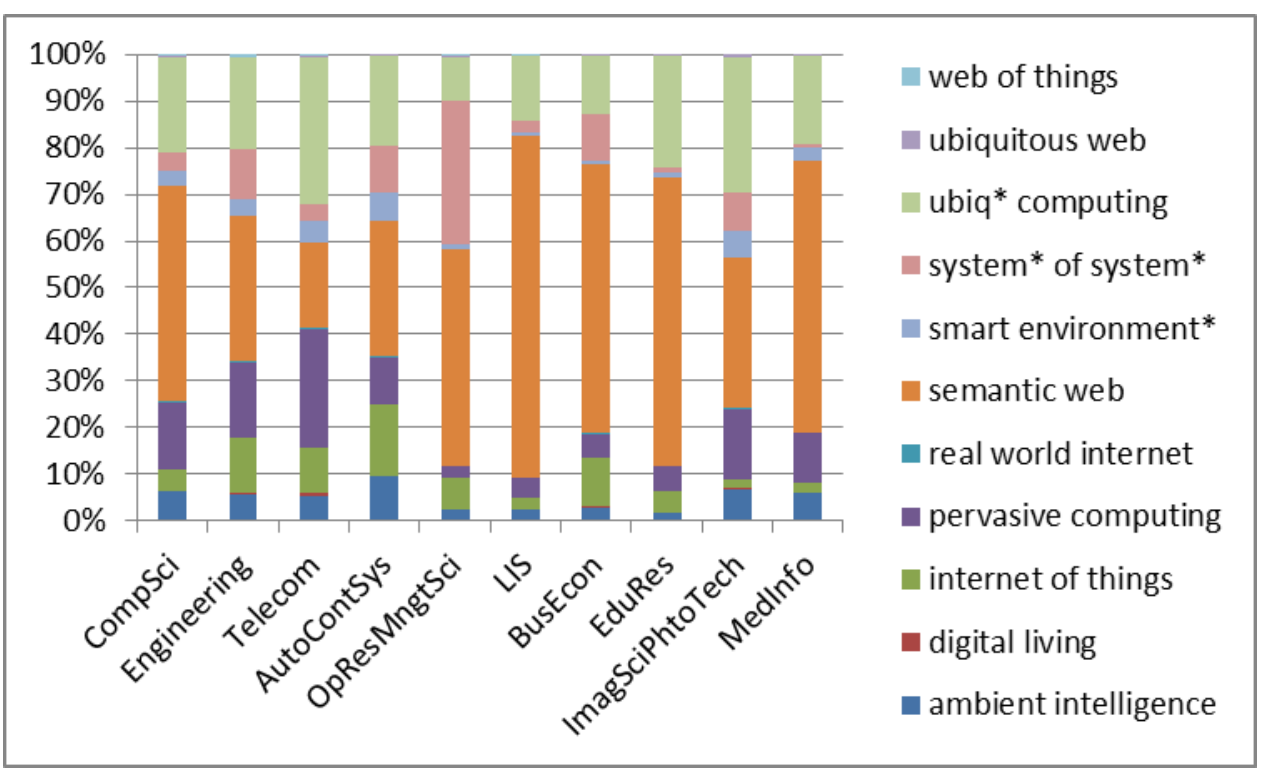

Figure $\mathbf{4 b}$. The ratio of presence of each concept within the top 10 research areas.

\section{Dispersion of concept use in different geographic boundaries}

In reviewing some key documents at the initial stages of our study, we noticed a potential variation in the use of the terms based on geographic locations. Accordingly, an early question became whether the level of use of different terms varies in relation to geographical regions. This was put to test by looking at the spread of the use of terms over national and geographical boundaries. As shown in what follows, the results supported our conjecture.

Table 7

List of countries that are associated with 100 or more documents in the examined publications

\begin{tabular}{lrlr}
\hline Countries/Territories & Docs & Countries/Territories & Docs \\
\hline USA & 3.532 & Ireland & 318 \\
China & 3,161 & Switzerland & 290 \\
Germany & 1,553 & Finland & 270 \\
England & 1,534 & Portugal & 249 \\
South Korea & 1,340 & Brazil & 248 \\
Spain & 1,225 & Belgium & 227 \\
Italy & 1,165 & Scotland & 197 \\
Japan & 775 & Sweden & 193 \\
France & 691 & Romania & 180 \\
Canada & 562 & Singapore & 160 \\
Greece & 500 & Poland & 124 \\
Australia & 492 & Norway & 120 \\
Netherlands & 463 & Denmark & 119 \\
Taiwan & 455 & Mexico & 116 \\
Austria & 397 & Iran & 110 \\
India & 327 & Turkey & 100 \\
\hline
\end{tabular}


We first analysed the spread of publications by the country of authors connected to each of the items. There were in total 103 countries involved. We found that the USA is the most productive country when the total publications on all terms are considered (Table 7).

As shown, 33 countries at the top of the list are each associated with 100 or more documents; of these the first 22 countries stand for one or more per cent of the documents. In other words, 81 countries each are associated with less than $1 \%$ of the documents.

This again forms a long tail where a few countries and institutions are associated with the bulk of the documents, while a long list of countries and or institutions were associated with very few documents each. Although this country overview is interesting, there are variations that are not distinguished. We therefore extended our examination of the spread of concepts over geographical boundaries in more details as presented below.

\section{The extent of institutional affiliations}

Table 7 highlighted the dominance of the USA in the production of scholarly publications on the identified concepts. When the study was extended, we found that this dominance is not fully mirrored in an analysis of the top institutions affiliated with the authors. As shown in Table 8, an American university first appears in the list of top organizations at position 7.

In our dataset, 712 items did not include information about the authors' organizational affiliations. In the rest of the material there were in total 5843 organizations identified. We sorted the records according to the number of documents associated to each organization. A list of 27 institutes, with which 75 or more documents were associated, is presented in Table 8. The number of organizations, with less than 10 documents each, was 5257, and the number of those with only one document was 3508, forming a very long tail.

Table 8

\begin{tabular}{lcclrr} 
Organizational affiliation (> 75 documents) & & & \\
\hline Organizations & \# Docs & \% & Organizations & \# Docs & \% \\
\hline Chinese Acad Sci & 170 & 0.8 & Sungkyunkwan Univ & 99 & 0.5 \\
Zhejiang Univ & 160 & 0.8 & Vienna Univ Technol & 96 & 0.5 \\
Univ Southampton & 155 & 0.7 & Univ Politecn & 95 & 0.5 \\
Univ Manchester & 132 & 0.6 & Univ Washington & 94 & 0.5 \\
Open Univ & 131 & 0.6 & Georgia Inst Technol & 93 & 0.4 \\
Beijing Univ Posts Telecommun & 129 & 0.6 & Vrije Univ & 93 & 0.4 \\
MIT & 127 & 0.6 & Univ Illinois & 90 & 0.4 \\
Shanghai Jiao Tong Univ & 123 & 0.6 & Wuhan Univ & 88 & 0.4 \\
Univ Karlsruhe & 117 & 0.6 & Kyung Hee Univ & 82 & 0.4 \\
Carnegie Mellon Univ & 113 & 0.5 & Univ Tokyo & 82 & 0.4 \\
Univ Carlos Iii Madrid & 113 & 0.5 & IBM Corp & 81 & 0.4 \\
Univ Murcia & 113 & 0.5 & Univ Cambridge & 80 & 0.4 \\
Stanford Univ & 107 & 0.5 & Yonsei Univ & 75 & 0.4 \\
Korea Univ & 101 & 0.5 & & & \\
\hline
\end{tabular}

The large number of organizations involved in so many different countries shows that familiarity with these concepts is extended to a wide area across various institutions, indicating the relevance of the present paper. 
This heterogeneity could also be seen in the bibliographic coupling of organizations (Figure 5) in which the authors were active at the time of publication. We find universities from many parts of the world. Asian universities have a strong presence, and so do universities from nonEnglish speaking countries in Europe. It is worth noting that although the U.S. is certainly present, it does not dominate the map in any way. It is also worth noting traces of the securityacademic complex (Sandia/Los Alamos National Labs, Mitre Corp.), while commercial corporations like Boeing and Oracle, as well as government agencies such as NASA and NOAA are also present.

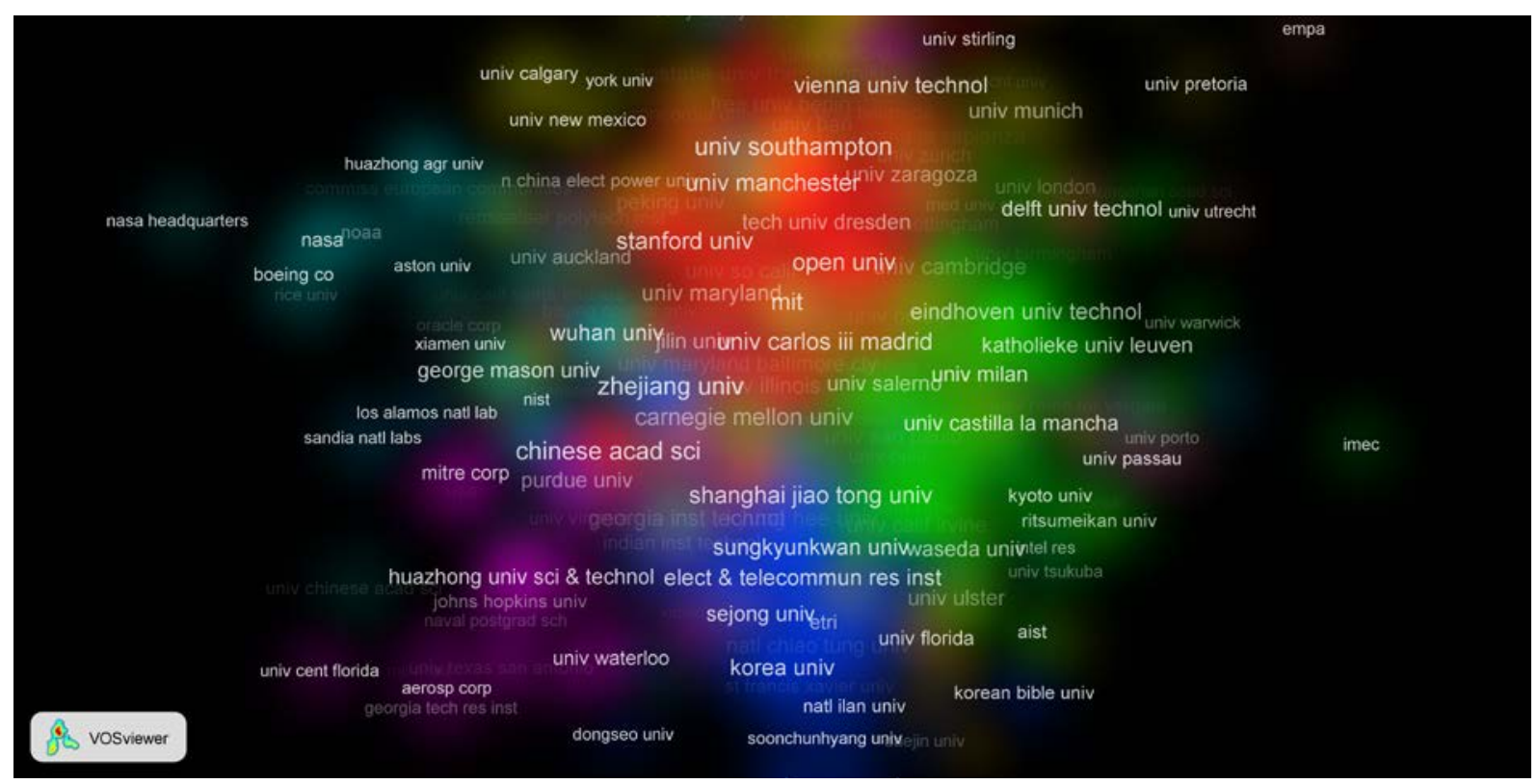

Figure 5. Bibliographic coupling of 1,045 organisations having more than 5 papers in the set.

\section{Spread of concept use in different geographical regions}

As the EU countries may be seen to form a unit comparable with that of the USA, we further investigated the level of publications in different combinations of countries. We first subdivided the 103 countries into groupings of $\mathrm{EU}_{28}$; Europe-Other; USA; America-other (N/C); South America; Africa; China; Asia (rest); Australia/Oceania. In these groupings the results became as shown in Table 9:

Table 9:

Share of the total publications per each of 9 country-groupings

\begin{tabular}{lc}
\hline Country group & \% of total publications \\
\hline EU & 44,47 \\
Asia (rest) & 15,94 \\
USA & 15,40 \\
CHINA & 13,67 \\
Europe -Other & 2,63 \\
Australia / Oceania & 2,57 \\
America-other (N/C) & 2,51 \\
South America & 2,05 \\
Africa & 0,75 \\
\hline
\end{tabular}


In this grouping we found that publications by authors with an affiliation within EU formed a clear majority followed by those from Asia (rest), USA and China.

Considering the low rate of publications in groups at the bottom of the list, we formed new regional divisions comprising: USA, Europe, China, Asia (rest), and Other. The analyses in following sections are based on this regional re-grouping.

As the regional pattern for overall data may vary from the pattern related to individual terms, we examined the spread of use of each of the eleven terms in relation to geographical location in two different ways as shown below.

\section{Level of publications on each term per region}

We found that the highest number of documents on ambient intelligence, pervasive computing, and semantic web are produced by authors with affiliations within Europe (Figure 6). In particular, the number of European publications on semantic web is by far greater than the publications (more than twice) on the same term by authors from either the USA or China.

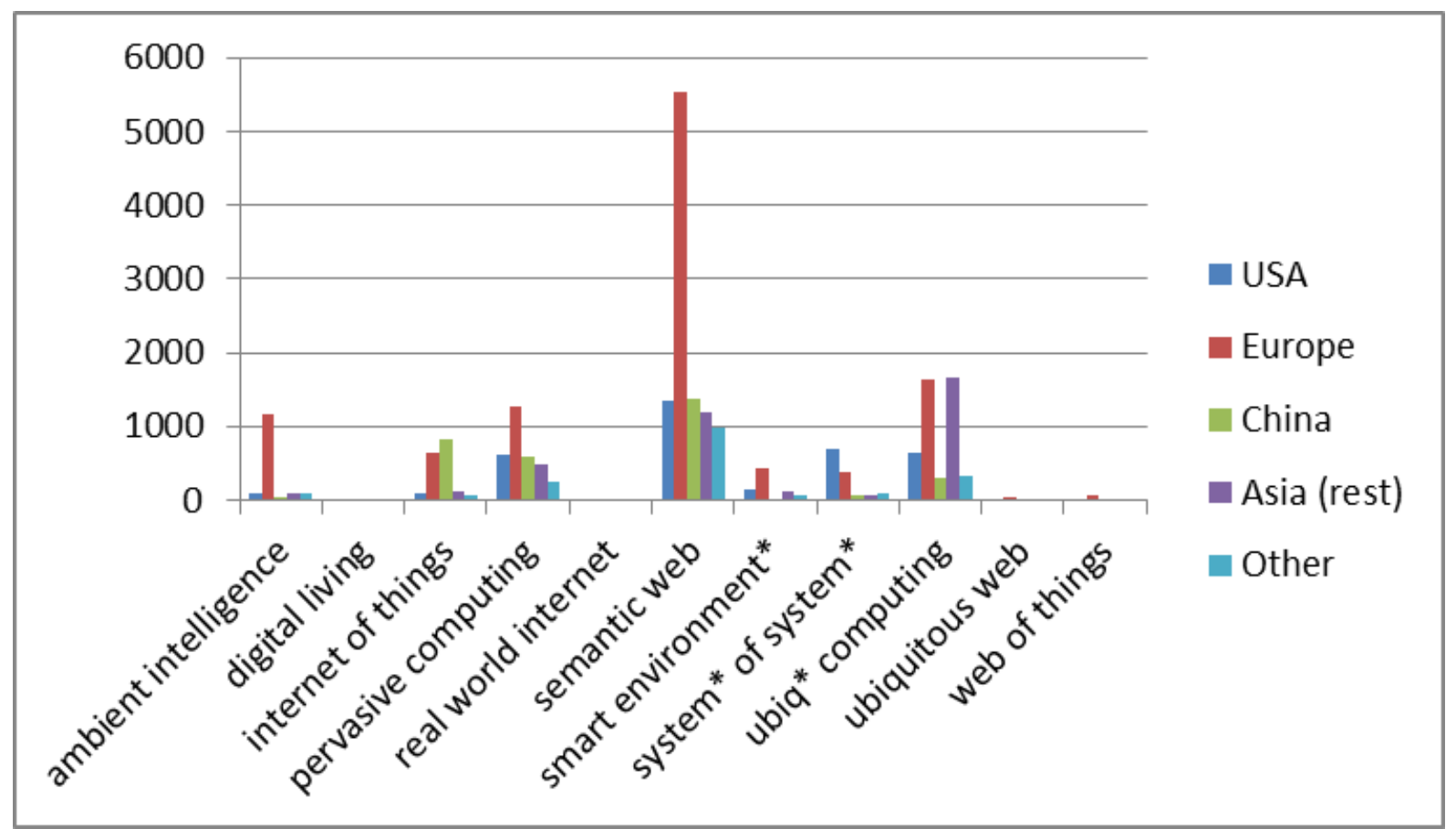

Figure 6. Extent of use of concepts (subdivided per geographical locations).

When it comes to those terms with fewer numbers of publications (somewhat difficult to decipher from Figure 6 due to considerable variations of documents per term), the terms "ubiquitous web" and even more so "web of things" have a stronger presence in Europe than the other regions. The term "digital living" is mainly referred to in documents by authors from the region classed as Asia (rest) while the referral to "real world internet" is more evenly spread across all regions.

The findings highlighted several surprising patterns. Based on observations in an initial limited literature reviews, it was expected that the USA would be the country of origin for majority of the documents on "ubiq* computing". However, the highest number of publications related to that concept was associated with Asia (rest) and even Europe surpassed the USA in this regard. Even a breakdown of the regions by countries (see Figure 11 later on 
in the document) showed that South Korea, as an individual country, surpassed the USA in this category of documents.

Furthermore, based on adoption of the term "internet of things" by the European Commission (as mentioned before), we had expected Europe to be the leading region in the use of that term. We found that this was not the case; the author-country dominant in the use of this term was instead China. It was further notable that Europe had a relatively strong presence in association to all the concepts.

To form a better representation of the spread of the terms across different geographical subdivisions, Figure 7 shows the ratio of regional representation per term.

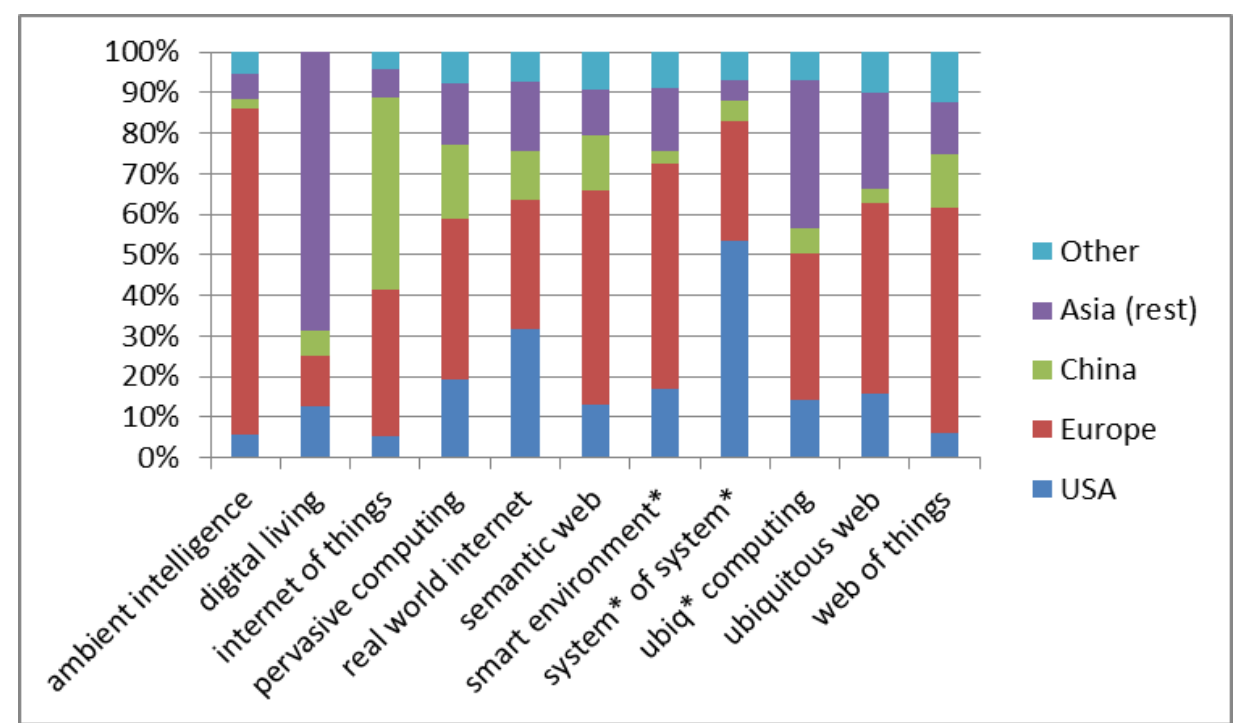

Figure 7. Spread of documents in different geographical locations (as per centage of total documents on each term).

As shown, publications by authors affiliated with European institutions are dominant in "ambient intelligence", "pervasive computing", "semantic web", "smart environment", "ubiquitous web” and "web of things".

\section{Ratio of use of each term per region}

The concept-region analysis was then reversed in order to look the levels of use of terms per geographical categories. The results are shown in Figure 8. As expected, "semantic web" has the highest number of publications in most regions, but surprisingly not in Asia (rest). In that region, "ubiq* computing” was most frequently used.

The term "system* of system*" has its strongest presence in the USA (holding second place after "semanic web"); and "internet of things" has strongest presence in China. In Asia (rest), the terms with most publications is "ubiq* computing" which also has a strong presence in in Europe. The term "internet of things" has a somewhat greater presence in China and Europe, still compared with other terms, it appears as a lesser prevalent term. This modest appearance is, however, challenged in the growth analysis that we present later on in this paper (Figure 11). 


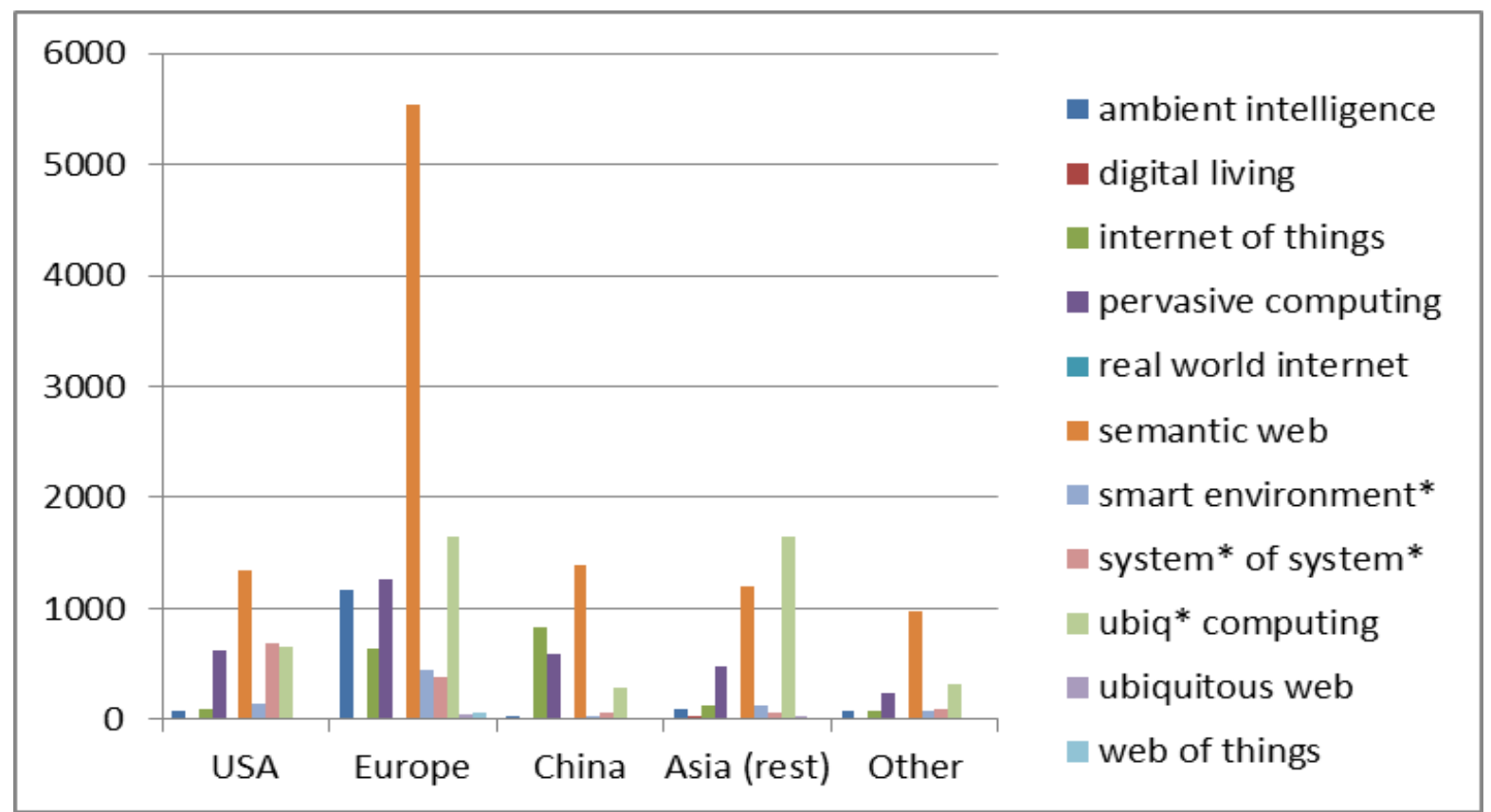

Figure 8. Extent of documents per region subdivided by specified terms.

In the lesser frequent terms, "web of things" has a stronger presence in Europe, China, and Other; "ubiquitous web” in the USA, and "digital living” in Asia (rest).

The same information but in terms of the per centages of total documents associated to each of the regions can be presented as in Figure 9.

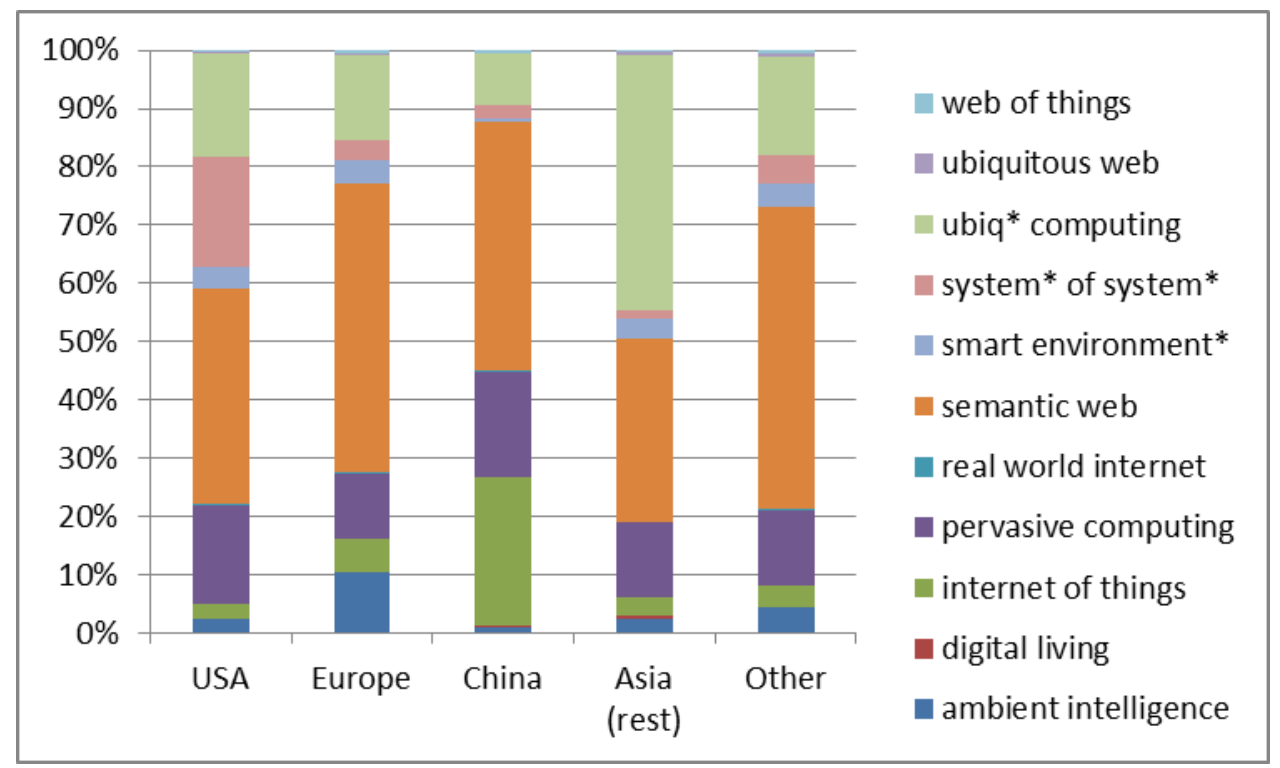

Figure 9. Spread of documents on each term as per centage of total number of documents in each geographical region.

Due to the large numbers of countries involved and difficulty in including all of these in our representations, the analysis above were based on our five regions. We, however, have conducted similar analyses at county level and have found that some countries stand out in relation to some of the terms. Figure 10 represents the ratio of term use per countries. 


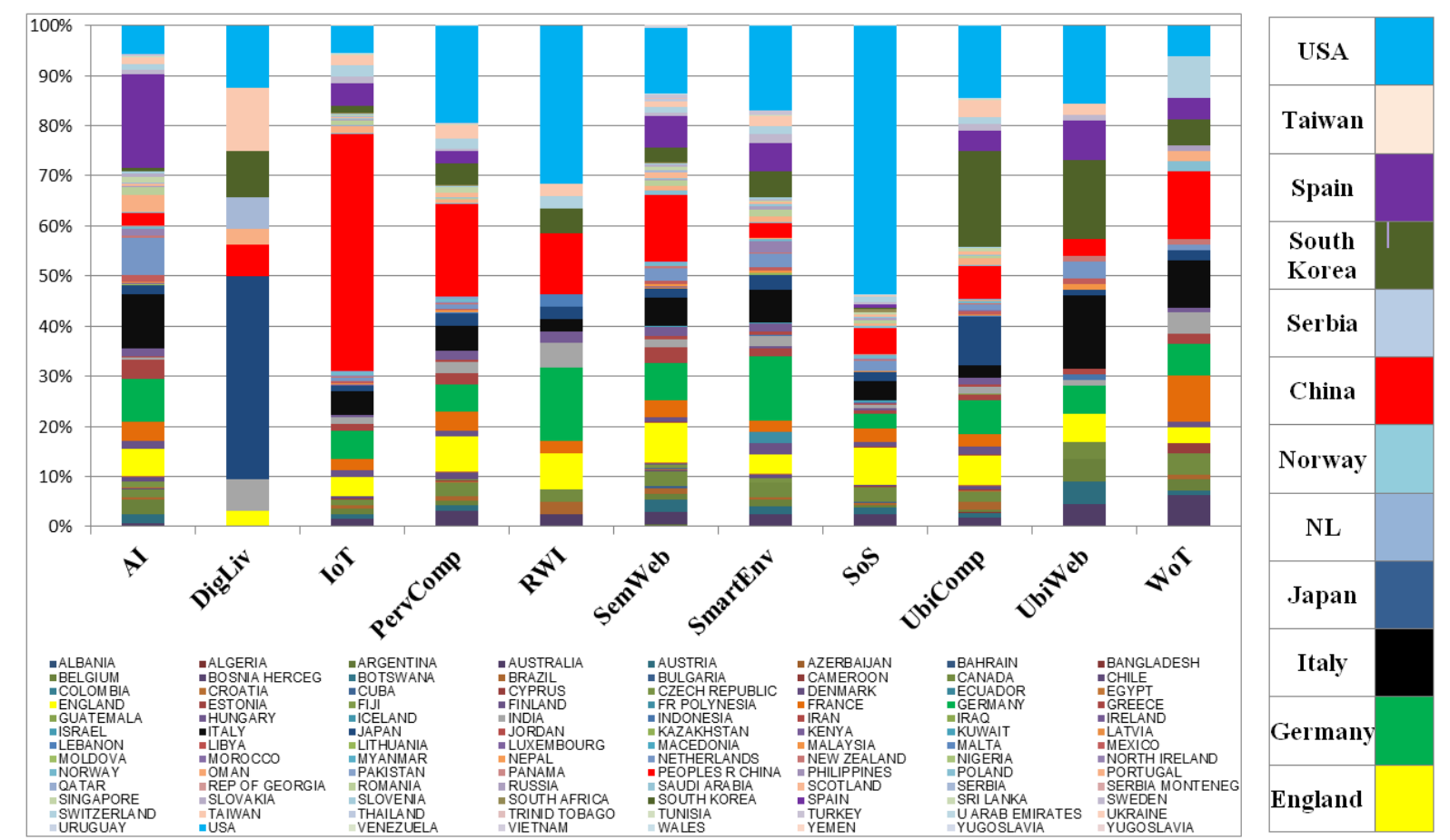

Figure 10. Ratio of term use in different countries.

We have highlighted the countries associated with greater number of publications in bright colours to facilitate visibility.

Our results thus far present the spread of documents over a wide range of terms and the extent of use of terms in different geographical locations, indicating differential term use in relation to locations. In the next section we discuss the temporal development of the different terms.

\section{Temporal development of scholarly publications on each term}

In Table 10, we include the year of the earliest publications on each of these terms as they appear in our dataset. The entries in Table 10 are re-organized in order of first year of publications.

Table 10

Number of years since the first publication on each term

\begin{tabular}{lcc}
\hline \multicolumn{1}{c}{ Search term } & $\begin{array}{c}\text { First year of } \\
\text { publications }\end{array}$ & $\begin{array}{c}\text { Average } \\
\text { publications/yr }\end{array}$ \\
\hline system* of system* & 1971 & 29.2 \\
semantic web & 1990 & 395.6 \\
ubiq* computing & 1992 & 196.9 \\
smart environment* & 1994 & 35.8 \\
pervasive computing & 1996 & 165.1 \\
ubiquitous web & 1998 & 5.4 \\
real world internet & 1999 & 2.8 \\
digital living & 2001 & 2.9 \\
ambient intelligence & 2001 & 104.6 \\
internet of things & 2002 & 135.3 \\
web of things & 2008 & 12.3 \\
\hline
\end{tabular}


As shown, some of these terms (such as "web of things") are relatively new. The term "system* of system*" has been in use the longest but "semantic web", the term second longest in use, has the largest number of publications. That is, the numbers of accumulated publications on different terms are not linearly proportional to the years that the terms have been in use. For example, the numbers of publications on "internet of things" and "ambient intelligence" are larger than the number of terms that have been in use longer such as "ubiquitous web", "real world internet" and so on. As shown, the average number of publications per year is highest with regards to "semantic web".

What the average number does not specify is the pattern of growth of these concepts over the years. We therefore extend our analysis to include the longitudinal development of each of the terms over the years. This is shown in Figure 11.

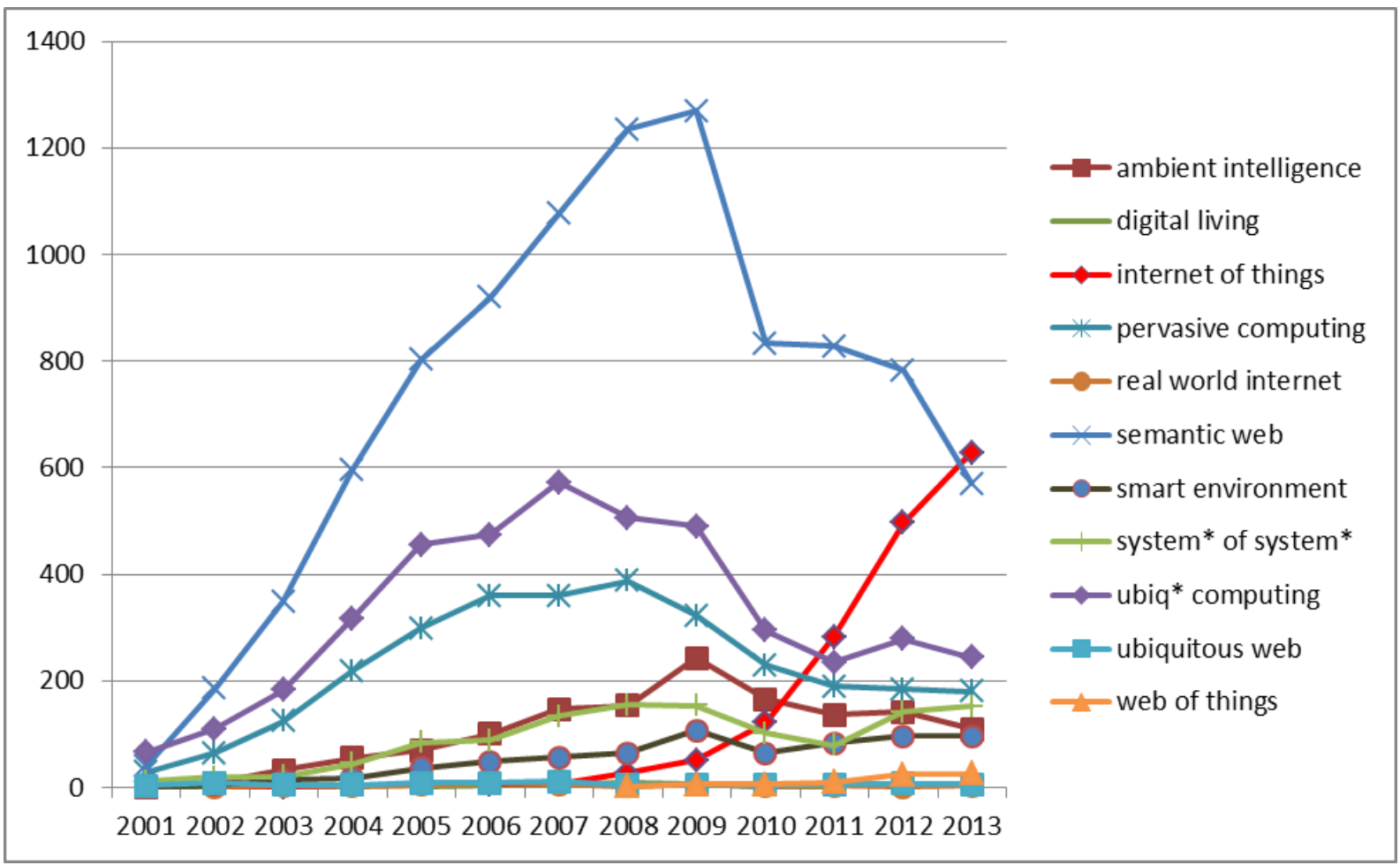

Figure 11. The longitudinal growth of publications on each of the terms.

As shown, the number of documents on the terms "real world internet", and "digital living" are too few for them to be visible in Figure 11. Even the curves related to "ubiquitous web", and "web of things" remain very close to the $x$ axis. What we otherwise observe is the downward trend for most of the terms. The peak year for the number of documents on "semantic web" has been 2009 and for "ubiq* computing" 2007. A double peak is found in relation to some of the terms such as "system* of system*" with the most number of publications on that term being in 2008. The trend related to the term "internet of things" stands out. Here, we find that the number of publications related to IoT have been on continuous rise so far. Indeed in 2013 documents on this term topped the number of publications as compared with all the other terms (even surpassing "semantic web"). Although not included in this presentation, this trend seems to even continue in 2014.

\section{Discussion}


In this paper, we have identified and provided an outline of eleven different concepts, which are commonly used in depictions of future visions as afforded by technology. We have determined the extent of use of these concepts and have identified that the pattern of their use varies based on disciplinary and geographical boundaries as well as over time.

The lack of formal definitions and conceptual demarcations that we found could serve as an explanation of the interchanged uses of concepts in a number of reviewed documents where the discussion goes beyond specialized, term specific, matters. The absence of clear distinctions between terms seems to afford random replacement of terms with one another. Therefore, it was surprizing that although much of the documents reviewed early on in our study did not demonstrate a clear demarcation of the terms, still the overlap in uses of these concepts in the dataset was relatively minimal, indicating a low mutual dependency. Further analyses, however, showed a tie between the uses of terms and geographical locations. Our study also suggested preferences of terms based on disciplinary belonging. These could potentially clarify the relatively minimal overlaps in the term use. That is, the study suggests that the choice of terms is not always based on conceptual distinctions between the terms and theoretical reflections. Instead, it appears that at times other factors such as trends and preferences related to geographical regions or disciplinary belonging also influence the choice. This is an interesting indication that could be further investigated.

As shown, several new related terms have come about in short spaces of time. The terms "ubiquitous web”, "digital living”, "real world internet”, “internet of things" and "ambient intelligence" had their first appearance in scholarly publications within a five year period. It would be valuable to determine whether the areas of investigations could be clearly distinguished in relation to these terms. Another point worth pointing out is that although the accumulated number of documents on terms such as "semantic web" and "ubiq* computing" are by far greater than some of the other terms, the number of publications on these and most of the other terms have had their peak in earlier years and are now following a downward trend. The only term that so far has followed an upward curve and which indeed topped the number of publications in 2013 is that of "internet of things". It would be interesting to follow the development of that term in the upcoming years.

The advent of information technology has been described in terms of technological revolution and compared with the industrial revolution. It has also been associated with major societal implications and changes in older forms of social structure (e.g. Castells, 1996). The technological developments envisioned by the studied concepts involve even greater societal implications that are in need of urgent critical reflections. As presented, none of the identified concepts has assumed an overarching unifying role to facilitate conflation of related discussions. Furthermore a lack of clarity in concept definitions persists. The examination of scholarly literature related to the identified concepts indicates a dispersion of closely-related discussions and concerns across a wide range of concepts and publication sources. This setting does not facilitate awareness of on-going discussions in different areas. The process of writing this paper is a good demonstration of the difficulties in identifying and gaining access to all the potentially relevant discussions. The identification of these eleven concepts involved a lengthy investigation, where a couple of the terms were identified late in the process, and even one (i.e. "system of systems") was added after the first review process. The laborious task of identifying the relevant terms for us as information specialist could indicate that such a task cannot be an easy endeavour for all those who need to be aware of (a) the existence of these terms and (b) the presence of discussions related to each of them. 
These terms concern world-wide transformation of information infrastructure and yet engagement in related discussions remains limited in many countries around the world. This entails a democratic or perhaps post-colonial problem of information practices of the future being designed by a few nations of the world. Many questions remain. What we propose here is that there is a need for further conceptual clarifications and conflation of discussions as a first step towards a broader analysis of, and reflection upon, the potential societal implications of such technology rich future visions. Although concerns regarding privacy, security and trust are taken up in association to some of these terms, it is difficult to tease out the core underpinning views on privacy. On one hand, some of the visions strive to place the control in the hands of users. On the other hand, it is not presented how this is to be done when trillions of sensors and cryptographic algorithms black-box the communication between objects linked to individuals and remove the control from the human users. What are the faith of citizenry and authoritative power structures in the face of mass surveillance that such technologies enable? What political decisions are needed to protect the rights of all the individuals and not just a selected few? What are the societal implications of the technological developments? These and many other vital questions need further research.

The aim of this paper has been a lot more modest than to attempt such a task. This paper provides an initial overview of the flora of related concepts. Technological innovations, which are the core of the discussions associated to these concepts, are of important societal relevance. What is needed to be studied further, and in more depth, is the type of issues that are addressed in association to each of these concepts and to examine the nature and extent of societal concerns that are being considered.

\section{References}

Ackoff, R. L. (1971). Towards a System of Systems Concepts. Management Science Series a-Theory, 17(11), 661-671.

Ashton, K. (2009), “That 'Internet of Things' Thing - In the real world, things matter more than ideas”“, RFID Journal, available at: http://www.rfidjournal.com/article/view/4986, (accessed Feb 12, 2013).

Athique, A. (2013), Digital Media and Society - An Introduction, Polity Press, Cambridge

Augusto, J. C., \& Aghajan, H. (2009), “Editorial: Inaugural issue”, Journal of Ambient Intelligence and Smart Environments, Vol. 1 No. 1, pp. 1-4.

Augusto, J. C., Nakashima, H., \& Aghajan, H. (2009), Ambient Intelligence and Smart Environments: A State of the Art. In Nakashima, H., et al. (Eds.), Handbook on Ambient Intelligence and Smart Environments, Springer Verlag, New York.

Badger, M., Bushmitch, D., Agnish, V., Cozby, R., Fikus, J., Halloran, F., . . Ieee. (2012). Laboratory-Based End-To-End Network System of Systems Integration, Design and Risk Reduction: Critical Activity for System of Systems Integration Directorate and the Army 2012 Ieee Military Communications Conference.

Bastian M., Heymann S., Jacomy M. (2009). Gephi: an open source software for exploring and manipulating networks. Third International AAAI Conference on Weblogs and Social Media. San José, CA.

Berners-Lee, T., Hendler, J., \& Lassila, O. (2001), “The Semantic Web”, Scientific American, Vol. 284 No. 5 , pp. 29-37.

Billsus, D., Brunk, C. A., Evans, C., Gladish, B., \& Pazzani, M. (2002), “Adaptive Interfaces for Ubiquitous Web Access “, Communications of the ACM, Vol. 45 No. 5, pp. 34-38.

Boyack, Kevin W. "Mapping knowledge domains: Characterizing PNAS” Proceedings of the National Academy of Sciences 101.suppl 1 (2004): 5192-5199.

Castells, M. (1996), The Rise of the Network Society (Vol. I: The Informaiton Age: Economy, Society and Culture), Blackwell, Cambridge, MA. 
Chen, E., Thiam, T. H., Issac, B., \& Huat Nguan, T. (2006), Analysis of IPv6 Network Communication Using Simulation, Paper presented at 4th Student Conference on Research and Development (SCOReD 2006), 27-28 June, 2006, Selangor, MALAYSIA, available at: http://ieeexplore.ieee.org/stamp/stamp.jsp?tp=\&arnumber=4339298, (accessed Jan 15, 2012).

Commission of the European Communities (2008), Communication on future networks and the internet, (Communication from The Commission to The European Parliament, The Council, The European Economic and Social Committee and The Committee of The Regions), Brussels: Commision of the European Communities.

Commission of The European Communities (2009), Internet of Things - An action plan for Europe (Communication from the Commission to the European Parliament, the Council, the European Economic and Social Committee and the Committee of the Regions: Report COM(2009) 278 final), Brussels: Commision of The European Communities.

Connaway, L. S., \& Powell, R. R. (2010). Basic research methods for librarians. ABC-CLIO, Santa Barbara, CA.

Cook, D. J., \& Das, S. K. (2005), Smart Environments - Technologies, Protocols, and Applications, John Wiley and Sons. Inc., Hoboken, New Jersey

Ducatel, K., Bogdanowicz, M., Scapolo, F., Leijten, J., \& Burgelman, J-C. (2001), “Scenarios for Ambient Intelligence in 2010 - Final Report”. Retrieved from: $\mathrm{ftp} / / / \mathrm{ftp} . c o r d i s . e u r o p a . e u / p u b / i s t / d o c s / i s t a g s c e n a r i o s 2010 . p d f$ (accessed September 15, 2012).

Finkelstein, A. C. W., Savigni, A., Kappel, G., Retschitzegger, W., Kimmerstorfer, E., Schwinger, W., ... Feichtner, C. (2002). Ubiquitous Web Application Development - A Framework for Understanding. Paper presented at the 6th World Multiconference on Systematics, Cybernetics and Informatics (SCI), Orlando, Florida. Retrieved from: http://www.cs.ucl.ac.uk/staff/A.Finkelstein/papers/uwa.pdf.

Garfield, E. (1979). Citation Indexing: Its Theory and Application in Science, Technology, and Humanities. New York: Wiley.

Greenfield, A. (2006). Everyware: The dawning age of ubiquitous computing. Berkeley, CA: New Riders.

Guinard, D., \& Trifa, V. (2009). Towards the Web of Things: Web Mashups for Embedded Devices. Paper presented at the Workshop on Mashups, Enterprise Mashups and Lightweight Composition on the Web (MEM 2009), Madrid, Spain, April 20-24, available at: http://www.vs.inf.ethz.ch/publ/papers/dguinard_09_WOTMashups.pdf (accessed September 15 2012).

Harbor Research (2010), The Internet of Things Meets The Internet of People - How The Internet of Things, Social Networks \& Creative Collaboration Will Shape Future Markets Opportunities: Whilte Paper), San Francisco, Boston, Zurich: Harbor Research, Inc.

Huang, C. M., Jang, M. Y., \& Chao, Y. C. (2000), “CTW: an integrated computer and telephoneaccessed WWW system”, Software: Practice and Experience, Vol. 30 No. 13, pp. 1485 1507.

IBM Research (n.d.), "Pervasive Computing“. Retrieved from: http://domino.research.ibm.com/comm/wwwr_thinkresearch.nsf/pages/pervasive.html (accessed Nov 15, 2012).

Jarneving, B. (2007). Bibliographic coupling and its application to research-front and other core documents. Journal of Informetrics, 1(4), 287-307.

Kelley, M., \& Pei, R. (1999). C4I2WS system of systems integration for the future army. In N. L. Faust \& S. Kessinger (Eds.), Modeling, Simulation, and Visualization for Real and Virtual Environments (Vol. 3694, pp. 215-222).

Kessler, M. M. (1963). Bibliographic Coupling Between Scientific Papers. American Documentation, 14(1), 10-25.

Knichel, D. G. (2010). Life After Future Combat System, a Family of Ground Robotic Systems. In G. R. Gerhart, D. W. Gage \& C. M. Shoemaker (Eds.), Unmanned Systems Technology XII (Vol. 7692), Orlando, Florida.

Lakoff, G., \& Johnson, M. (2003 [1980]), Methaphores We Live By, The University of Chicago Press, Chicago. 
Liu, C., Zhou, X., \& Orlowska, M. E. (1998), Issues in Work flow and Web-based Work flow Systems, Paper presented at The 1998 Asia Pacific Web Conference (APWeb98), 27-30 September 1998, Beijing, China, available at: http://researchbank.swinburne.edu.au/vital/access/services/Download/swin:29802/SOURCE1, (accessed Jan 15, 2012).

Logenthiran, A., Pratiwadi, R., Logenthiran, D., Porebski, A., \& Thomas, D. W. (1998), Software Migration of Telecommunication Network Management Systems to the Web using CORBA and Java, Paper presented at The Thirty-first Hawaii International Conference On System Sciences, Kohala Coast, HI, available at: http://ieeexplore.ieee.org/stamp/stamp.jsp?tp=\&arnumber=649265, (accessed Jan 15, 2012).

Marquet, L. C., \& Ratches, J. A. (1998). Future directions of information systems in the Army After Next. In R. Suresh (Ed.), Digitization of the Battlespace Iii (Vol. 3393, pp. 20-26), Orlando, Florida.

McCain, K. W. (1986). Cocited author mapping as a valid representation of intellectual structure. Journal of the American Society for Information Science, 37(3), 111-122

McCain, K. W. (1991a). Core Journal Networks and Cocitation Maps - New Bibliometric Tools for Serials Research and Management. Library Quarterly, 61(3), 311-336.

McCain, K. W. (1991b). Mapping Economics Through the Journal Literature - An Experiment in Journal Cocitation Analysis. Journal of the American Society for Information Science, 42(4), 290-296.

Negroponte, N. (1995), Being Digital, Vintage Books, New York.

Orwat, C., Graefe, A., \& Faulwasser, T. (2008), “Towards pervasive computing in health care - A literature review”, Bmc Medical Informatics and Decision Making, Vol. 8 No. 26.

“Position Paper: Real World Internet”. (2009), Last modified 07:43, 6 May 2009. [Wiki], Retrieved from: http://rwi.future-internet.eu/index.php/Position_Paper (accessed October 15, 2012).

Rainie, L., \& Wellman, B. (2012), Networked - The New Social Operating System, MIT Press, Cambridge, MA.

Saha, D., \& Mukherjee, A. (2003), "Pervasive computing: A paradigm for the 21st century", Computer, Vol. 36 No. 3, pp. 25-31.

Sci2 Team. (2009). Science of Science (Sci2) Tool. Indiana University and SciTech Strategies, available at: https://sci2.cns.iu.edu.

Satyanarayanan, M. ( 2001), "Pervasive computing: vision and challenges”, IEEE Personal Communications, Vol. 8 No. 4, pp. 10-17.

Small, H. (1973). Cocitation in Scientific Literature - New Measure of Relationship Between 2 Documents. Journal of the American Society for Information Science, 24(4), 265-269.

Small, H. G., \& Griffith, B. C. (1974). The Structure of Scientific Literatures I: Identifying and Graphing Specialties. . Science Studies, 4 (1), 17-40.

Sundmaeker, H., Guillemin, P., Friess, P., \& Woelfflé, S. (Eds.), (2010), Vision and Challenges for Realising the Internet of Things, European Commission, Information Society and Media, Brussels.

The Council of Europe (2009), Internet governance and critical internet resources - a report prepared by the Council of Europe Secretariat), Strasbourg: Media and Information Society Division, Directorate General of Human Rights and Legal Affairs, Council of Europe.

Townsend, E. (2011), Technology Strategy Board - Driving Innovation, (Future Internet Report), London: ICT KTN (ICT knowledge Transfer Network).

van Eck, N. J., \& Waltman, L. (2011). Text mining and visualization using VOSviewer. ISSI Newsletter, 7(3), 50-54.

van Raan, A. F. J. (2005). Measuring Science, In Moed, H. F., Glänzel W. and Schmoch, U. (Eds), Handbook of Quantitative Science and Technology Research: The use of Publication and Patent Statistics in Studies of S\&T Systems, pp. 19-50, Dordrecht: Springer

Web of Science (2007), "Web of Science 8.0 Workshop”, 56, available at: http://ipscience.thomsonreuters.com/m/pdfs/mgr/ws-wos-8-0-0807.pdf.

Weiser, M. (1991), “The Computer for the 21st Century - Specialized elements of hardware and software, connected by wires, radio waves and infrared, will be so ubiquitous that no one will notice their presence”, Scientific American, Vol. 265 No. 3, pp. 94-104. 
Weiser, M. (1993a), “Some Coputer Science Issues in Ubiquitous Computing”, Communications of the ACM, Vol. 36 No. 7, pp. 75-84.

Weiser, M. (1993b), “Ubiquitous computing”, Computer, Vol. 26 No. 10, pp. 71-72.

Weiser, M. (1995), “The Last Link: The Technologist’s Responsibilities and Social Change”, Computer-Mediated Communication Magazine, Vol. 2 No. 4, p. 17.

Weiser, M., Gold, R., \& Brown, J. S. (1999), "The origins of ubiquitous computing research at PARC in the late 1980s", IBM Systems Journal, Vol. 38 No. 4, pp. 693-696.

White, H. D., \& Griffith, B. C. (1981). Author Cocitation - A Literature Measure of Intellectual Structure. Journal of the American Society for Information Science, 32(3), 163-171.

Whitley, R. (2000), The Intellectual and Social Organisation of the Sciences (2nd ed.), Oxford University Press, New York.

Yachir, A., Amirat, Y., Chibani, A., \& Badache, N. (2012), “Towards an event-aware approach for ubiquitous computing based on automatic service composition and selection”, Annals of telecommunications - Annales des télécommunications, Vol. 67 No. 7-8, pp. 341-353.

York, J., \& Pendharkar, P. C. (2004), "Human-computer interaction issues for mobile computing in a variable work context”, International Journal of Human-Computer Studies, Vol. 60 No. 5-6, pp. 771-797.

Zelkha, E., \& Epstein, B. (1998), From Devices to 'Ambient Intelligence’: The Transformation of Consumer Electronics, Paper presented at Digital Living Room Conference, Philips, available at: http://www.epstein.org/brian/ambient_intelligence.htm [5].

\begin{abstract}
About the authors
Dr Nasrine Olson is a Senior Lecturer at the Swedish School of Library and Information Science and her research interests include Social Media Studies, mechanisms of control, decision-making, and social order. Dr Nasrine Olson is the corresponding author and can be contacted at: Nasrine.

Olson@hb.se

Jan Michael Nolin is a Professor in Library and Information Science at the Swedish School of Library and Information Science. His research interests include Internet studies, Social Media Studies, and Scholarly Communication.

Gustaf Nelhans has a PhD in Theory of Science at the University of Gothenburg Sweden, specializing in meta-studies of bibliometrics.
\end{abstract}

\footnotetext{
${ }^{1}$ Ashton (2009) claims "I'm fairly sure the phrase "Internet of Things" started life as the title of a presentation I made at Procter \& Gamble (P\&G) in 1999". However, we did find a reference to a document that supposedly has been presented in 1997, at a conference titled "Internet of Things" (http://digital.library.adelaide.edu.au/dspace/handle/2440/62549). Unfortunately, even after a lengthy investigation, we were not able to verify or reject the existence of that conference.

${ }^{2}$ Date delimitation was chosen to enable repetition of the study. However, we found that retrospective additions are made in WoS and hence a search with the same criteria returns increased results as time goes by.

${ }^{3}$ Please note that the data presented in rest of this paper were searched for and retrieved on the 3rd of June, 2014 (retried items 21,997), however the searches for the overlaps, presented in Table 2, were conducted on August 25th 2014 (retrieved items 22,184). Although exact same search criteria was used, due to lapse of time the numbers in Table 2 do not fully correspond with the rest of the data presented and accordingly the level of overlap became larger (i.e. 1,153 rather than 1,055). As we have conducted the same set of searches numerous times on different occasion, we have found that pattern of overlap remains similar; therefore, we have chosen to include Table 2 regardless of the discrepancy in numbers due to search dates.

${ }^{4}$ VOSviewer removes stop-words and performs stemming of words that somewhat made our study problematic. Because stop-words are removed, prepositions such as 'of' are removed. Some phrases that we are interested in, e.g. 'internet of things', were therefore omitted by the program. To remedy this, we created 'dummy phrases, such as 'internetofthing', where spaces, as well as the plural s's were
} 
removed. At a later stage, the original phrases where reinstated using the thesaurus function in VOSviewer. All of the 11 terms that were analysed in this study were entered in the thesaurus file to ensure that if these combinations were found in the data set, they were identified and used as phrases in the analysis. Additionally, the abbreviation 'iot' was added to the 'internet of things' phrase and so on.

${ }^{5}$ The authenticity of the documents found at this link has been confirmed by the authors. 